\title{
ESCAPE LEARNING AND "VICIOUS CIRCLE" BEHAVIOR UNDER PARTIAL AND CONTINUOUS REINFORCEMENT
}

\author{
By
}

KENNETH BOYD MELVIN, JR.

\begin{abstract}
A DISSERTATION PRESENTED TO THE GRADUATE COUNCIL OF THE UNIVERSITY OF FLORIDA

IN PARTIAL FULFILIMENT OF THE REQUIREMENTS FOR THE DEGREE OF DOCTOR OF PHILOSOPHY
\end{abstract}

UNIVERSITY OF FLORIDA

August, 1963 
UNIVERSITY OF FLORIDA

31262085522141 


\section{ACKNOWLEDGMENTS}

I wish to express my sincere appreciation to the following members of my supervisory committee for their interest, help and enlightenment: Drs. P. Brodkorb, B. N. Bunnel1, M. E. Shaw, and W. B. Webb. My gratitude is due former members of the committee: Drs. J. S. Brown, H. S. Pennypacker, and R. H. Waters, for their contributions.

I am especially grateful to Dr. H. D. Kimmel, Chairman of my committee, for his encouragement, interest, and cogent criticism.

The Graduate School and the Department of Psychology of the University of Florida have my gratitude for their financial assistance.

Finally, I wish to thank my wife, Bernice, for her help and understanding. 


\section{TABLE OF CONTENTS}

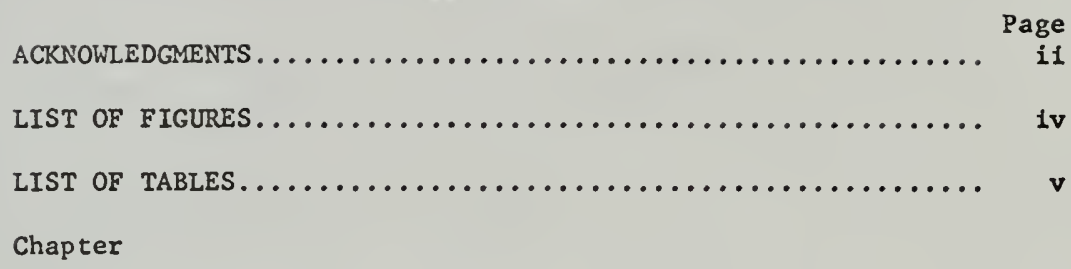

I. INTRODUCTION. .......................... 1

II. HISTORICAL REVIEW....................... 7

III. METHOD............................. 18

IV. RESULTS............................ 25

v. DIscussion.......................... 35

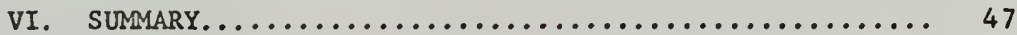

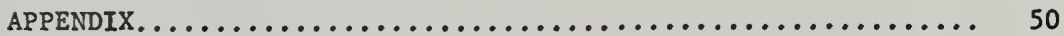

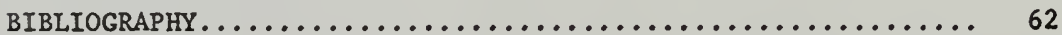




\section{LIST OF FIGURES}

Figure

1. Mean Number of Trials to Extinction for All Eight

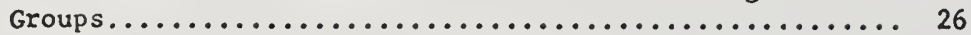

2. Mean Speed to Traverse the 6-ft. Runway for Eight

Groups on Each of Four Extinction Days............. 29

3. Mean Speed to Traverse the First 2-ft. Alley Section

for Eight Groups on Each of Four Extinction Days....... 32

4. Mean Speeds Exhibited by the Eight Groups in Each of the 2-ft. Sections of the Runway. Each Point Represents a Mean of Average Speeds for the First Three

Days of Extinction.......................... 34 


\section{LIST OF TABLES}

Table

1. Mean and Standard Deviation for Alley Running Speeds

( $1 / R T)$ on the Last Training Trial for All Eight Groups

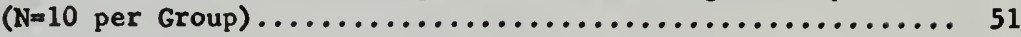

2. Analysis of Varisnce for Alley Running Speeds ( $1 / R T$ )

on the Last Trsining Trial........................ 52

3. Analysis of Variance for Number of Trials to Extinction..... 52

4. Analysis of Variance for Number of Trials to Extinction..... 53

5. Analysis of Varlance for Number of Trials to Extinction.... 53

6. Anslysis of Variance for Alley Running Speeds ( $1 / R T)$ over

Three Days of Extinction........................ 54

7. Analysis of Variance for Alley Running Speeds (1/RT) over

Three Days of Extinction....................... 55

8. Analysis of Variance for Alley Running Speeds (1/RT) over Three Days of Extinction........................ 56

9. Analysis of Varisnce for Section 1 Running Speeds (1/RT) over Three Days of Extinction.................... 57

10. Anslysis of Variance for Section 1 Running Speeds (1/RT) over Three Days of Extinction..................... 58

11. Analysis of Varisnce for Section 1 Running Speeds (1/RT) over Three Days of Extinction..................... 59

12. Analysis of Variance for Running Speeds ( $1 / R T$ ) Averaged over Three Days for Each of Three Alley Sections.......... $60^{\circ}$

13. Analysis of Varisnce for Running Speeds (1/RT) Averaged over Three Dsys for Each of Three Alley Sections.......... 61 


\section{CHAPTER I}

\section{INTRODUCTION}

The resolution of certain behavioral paradoxes has been a problem of interest to both clinical and experimental psychologists. One such paradox is seen in neurosis, where actions having unfavorable consequences may persist over long periods of time. In addition to this "neurotic paradox," other behavior which is both self-maintaining and self-defeating has long been in evidence, e.g., addictions, vices, and psychotic symptoms.

Such maladaptive behavior is not confined to humans, since through the use of special laboratory procedures animals can be trained to approach noxious stimulation in a consistent manner. One example of such behavior, which seems analogous in some respects to the neurotic paradox, has been labeled the "vicious circle" phenomenon by Mowrer (1950). Mowrer reported that this phenomenon was first observed by J. S. Brown in the following type of situation. A rat was trained to run down a short straight runway to eacape electric shock presented throughout the length of the runway. The escape was made by running into a "safe" goal box connected to the end of the runway. After training in this manner, the animal ran down the alley without any shock being applied. Such behavior occurred for a number of trials, but eventually it extinguished. If, however, a aection of the runway just in front of the goal box was kept electrifled, the running response 
showed a marked increase in resistance to extinction.

Although the vicious circle phenomenon would appear to merit a thorough experimental analysis, relatively little experimental work has been done in this area. Whiteis (1956) has confirmed the original effect, and other experiments have shown that punishment may facilitate resistance to extinction (Gwinn, 1949; Solomon, Kamin, \& Wynne, 1953). However, other invest1gators (Moyer, 1955, 1957; Seward \& Raskin,.1960) have not obtained confirmatory results although employing simflar techniques and situations. Two recent experiments reported by Brown, Martin, and Morrow (in press) have pointed out some possible reasons for these previous discrepancies. Their first experiment did not show any significant effects of shock as punishment for escape responses during extinction. Their second experiment, however, demonstrated that shocked rats resisted extinction significantly longer than non-punished rats. The following procedural changes characterized the second study relative to the first: (a) the intensity of the punishing stimulus was made more moderate (b) fewer escape training trials were given (c) the first trisis of extinction were given on the same day as the last trials of acquisition, rather than $22 \mathrm{hr}$. later and (d) a more gradual transition from shock during acquisition to no shock during extinction was introduced.

The present study was an attempt to determine the effects of a partial reinforcement schedule on both the vicious circle phenomenon and, more basically, the resistance to extinction of an escape response. An intermittent escape training procedure was one method of making the change from training to extinction less marked, since partially reinforced animals would have landed and run on a non-electrified grid occasionslly prior to 
extinction. Empirical evidence from a wide variety of situations has shown that resistance to extinction after partial reinforcement is greater than after continuous reinforcement (Lewis, 1960). Furthermore, a study by Jones (1953) has shown that an intermittent escape training schedule (a procedure in which shock is omitted on some percentage of the escape trials) results in greater resistance to extinction than a continuous schedule.

Thus, if an intermittent shock schedule during training established a more stable running response in the non-electrified segment of the runway, it might be expected that the vicious circle phenomenon might be enhanced. Since Jones' study had certain Iimitations (which are discussed in Chapter II), a further study of the effects of partial reinforcement on the resistance to extinction of an escape response seemed also desirable.

Theoretical considerations necessitated the evaluation of an. additional variable - the similarity of the percentage of shock trials during training to the percentage of shock trials during extinction. One of the three theories mentioned by Brown et al. (in press) as being consistent with their results is a form of the "discrimination hypothesis," As applied to the vicious circle phenomenon, this theory states that those subjects (Ss) receiving no shock in extinction would experience the most marked change from acquisition. For $\underline{\text { ss receiving }}$ shock in part of the runway during extinction, this change is less marked, which should result in comparatively more resistance to extinction. An alternative theory is that of Mowrer (1950). He maintains that the initial escape training results in the conditioning of fear to the 
cues provided by the buzzer, starting box, and alley. During extinction the rat runs because it is afraid; running produces shock, which retards or prevents the process of fear extinction; and fear reduction reinforces running. Guthrie's (1935) concept of negative adaptation is also applicable to the vicious circle phenomenon. According to Guthrie, aversive stimuli lose their power to evoke escape responses if they are repeatedly presented when responses that are incompatible with shock are prepotent. The noxious stimulus loses its escape-evoking power to the degree that it becomes a conditioned cue for the incompatible reactions. Applying this theory to the present situation, the tactual cues provided by shock are part of the stimulus complex to which running becomes conditioned during training. Shock thus becomes capable of evoking running reactions which are incompatible with non-running. During extinction, shocked animals persist longer in running because shock evokes and maintains forward-going behavior.

Both Guthrie's and Mowrer's interpretation would lead to a prediction that the use of a continuous shock condition in extinction (one in which shock is presented in the last 4-ft. of the alley on every trial) would result in greater resistance to extinction than a partlal shock condition. The discrimination hypothesis, on the other hand, would predict that a partial shock schedule during extinction would result in greater resistance to extinction than a continuous schedule, if the $\underline{S}$ had been trained under a similar partial schedule. Thus, the inclusion of groups having the same percentage of shock trials during both training and extinction allowed the discrimination hypothesis to be compared with the other two theorles. 
Shock was present during 33,67 or 100 per cent of the training trials for three different groups of rats. These groups were subdivided during extinction so that a portion of each group received either no shock at any time, 100 per cent shock in the last 4-ft. of the alley, or the same percentage of shock during extinction as had been given during training. This procedure resulted in the formation of eight groups, since the group which received 100 per cent shock in both training and extinction served in two conditions. Resistance to extinction was measured in terms of number of trials to extinction and various speed measures.

In the light of the available evidence and theory, the following hypotheses were formulated:

1. A shock escape response is more resistant to extinction when it is followed (during extinction) by punishment than when it is not, regardless of the percentage of reinforcement during training.

2. Partial reinforcement during training facilitates vicious circle behavior.

3. Partial reinforcement increases the resistance to extinction of an escape response.

It should be noted that Hypothesis Number 1 asserts simply that the vicious circle phenomenon will be obtained under the conditions of the experiment. Hypothesis Number 2 predicts more vicious circle behavior under conditions which are known to strengthen resistance to extinction in general. Hypothesis Number 3 predicts that the findings of Jones (1953) will hold under the present experimental conditions. No specific prediction was made regarding the use of the same percentage 
of shock during extinction as had been used during training, although it may be noted that the discrimination hypothesis would lead to a prediction of superior resistance to extinction for these groups over partially reinforced groups shifted to 100 per cent shock during extinction. Both Mowrer's and Guthrie's theory would predict a reverse outcome. 
CHAPTER II

\section{HISTORICAL REVIEW}

An analysis of the paradigm in which the vicious circle phenomenon has been produced reveals two main components. One such component is the original escape or avoidance training; escape training was preferred due to the limitations in control inherent in avoidance training. The second component is punishment, usually consisting of an aversive stimulus of the same nature as that used in the original escape situation. The punishment is also theoretically avoidable, but instead is approached and endured by the organism.

The present study contains a third component -- partial reinforcement. This term is used herein to denote a procedure which involves withholding the aversive stimulus on some escape training trials. It should be noted that such a procedure leads to a partial schedule of both shock onset and shock offset.

In the following historical survey, interrelationships between these three components were of primary interest. Major theories of punishment, and experiments in which organisms show approach toward or non-withdrawal from noxious stimuli, were also considered especially relevant.

$\underline{\text { Punishment }}$

Theory.--Although philosophy had earlier concerned itself with the problem of punishment, e.g., hedonism, the earliest major theory of 
punishment based upon experimentation seems to be that of Thorndike (1913). His 1 aw of effect stated the relationship of punishment to learning. Thus, when a modifiable connection was made and followed by an annoying state of affairs, its strength was decreased. This "annoying state of affairs" is equivalent to punishment and was defined by Thorndike as "... one which the animal does nothing to preserve, often doing things which put an end to it" (1913, p. 2).

Thorndike (1935) later modified his position, relegating punishment to a lesser role. In this later version, punishment was held to affect learning only indirectly. This indirect effect stems mainly from the punishment leading the animal to do something else in its presence, which makes him less likely to repeat the original $\underline{S-R}$ sequence. Thorndike also postulated an emotional state resulting from punishment, and stated that "...the impulse to make (the punished response) tends to arouse a memory of the punishment and fear, repulsion, or shame. This is relieved by making no response to the situation...or by making a response that is or seems opposite to the original response" (Thorndike, 1935, P. 80).

Later theories of punishment have elements in common with Thorndike's later theoretical position. Guthrie's (1935) contiguity interpretation and the avoidance hypothesis of Dinsmor (1954) emphasize the action of competing responses. Other theorists have stressed the role of an emotional state induced by punishment. Such emotional states are represented by Estes" "anxiety state" (1944), the "heightened tension" of Hilgard and Marquis (1940), and learned sources of drive such as "fear" or "anxiety" (Miller, 1948; Mowrer, 1950, 1960). These emotional states are conceived 
of as negative in character, and thus the reduction of such emotional states by non-punished responses is considered reinforcing.

Although theoretical explanations of punishment differ in some aspects, they generally support the contention that punishment inhibits the response associated with it either directly or through the elicitation of some entional reaction. An alternate reaction may then be reinforced by escape from punishment, reduction of the emotional state, or some other reinforcing agent.

Experimentally induced self-punishment.--A problem for both theory and experimentation has been to explain and analyze instances in which organisms endure and even seek out noxious stimuli. Although such "masochistic" behavior has been produced in the laboratory, relatively little has been done in the way of any systematic analysis.

Experimental work on this problem was conducted by Pavlov and his students (Pavlov, 1927). They found that noxious stimuli such as electric shock and wounding of the skin lost their aversive properties, if, when previously used as CSs for the presentation of food, their intensity was gradually increased. Thus, a dog would lose his defense reactions to a shock, and instead smack his lips and salivate in its presence after the shock had been paired with food. Similarly, Spragg (1940) has reported "relaxing" responses in drug-addicted monkeys to the sight and feel of a hypodermic needle. Another study (Slutskaya, 1928) found that infants who were pricked with a needle and then fed came to show anticipatory feeding (i.e., approach) responses to the sight of the needle. Very similar in approach to these experimental studies is the "reciprocal inhibition" or "desensitization" therapy of Wolpe (1958), who has reported considerable success with this technique. 
Masserman's (1946) studies of "experimental masochism" provide an example of organisms seeking out a noxious stimulus. In these studies cats were trained to press a switch to obtain food. Air blasts of gradually increasing intensity preceded the administration of the food. After such training, the cat would frequently work the switch to experience an air blast that was aversive to "normal" cats (Masserman, 1946, p. 57). The aversiveness of bright light to albino rats can also be reduced through "desensitization" training (Brown \& Melvin, 1963). They found that, after receiving pairings of bright light with food, a group of animals thus trained endured such a light longer than a control group. The reduction of 1 ight-escape tendencies was found to be an increasing function of the number of previous light-food pairings.

Holz and Azrin (1961), using three pigeons in a free-responding situation, found that punishment that had been paired with reinforcement increased response rate. Sandler (1962) has confirmed their findings using five tamarin monkeys in a similar situation.

Another type of maladaptive behavior which should be considered is fixation -- a behavioral phenomenon having common elements with the vicious circle phenomenon. Maier (1949) has shown that frustration produces very persistent responding to an incorrect cue ("abnormal fixations"). His basic thesis is that frustration results in a fixation or stereotype of an organism's response. Such an extremely persistent response is not responsive to alternation by punishment or reward and is a goal in itself, according to Maier.

Maier's theory of "behavior without a goal" has not gone unchallenged. 
Farber (1948) reported findings which suggest fixation resulting from shock may be the result of anxiety reduction. Wilcoxon (1952) pointed out that the creation of an insoluble problem resulted in a type of partial reinforcement for the animal. When he used a partial-reinforcement group in a Maier-type situation, it was more fixated than an insoluble problem group. In addition to partial reinforcement and anxiety reduction, frustration reduction may also contribute to the persistence of the "fixated" response (Kimble, 1961).

Studies in which electric shock administered after a choice point was found to facilitate learning (Muenzinger, 1934, 1948; Drew, 1938) are also relevant. While Muenzinger concluded that shock does not inhibit the punished response, but instead makes the animal more sensitive to the cues to be discriminated, other explanations have been offered. Mowrer (1950, p. 342) noted that while the wrong response resulted in non-reinforcement, the correct response, though punished by shock, was always followed by escape from both hunger and fear. Brown (1955) has interpreted Muenzinger's results in terms of the shock providing an increment to drive. Thus, the ongoing reaction, since it is dominant in the situation, will be facilitated rather than disrupted. This interpretation reconciles Muenzinger's results with the multiplicative drive theory of Hull (1943).

Still another variation of experimentally induced self-punishment is seen in the present experimental paradigm. The vicious circle phenomenon involves self-punishing behavior, which also may be extremely persistent. Previous studies of this phenomenon have been reviewed in Chapter I. However, it should be noted that the vicious circle phenomenon 
differs from the "masochistic" or "fixated" behavior reviewed above, in that the punished response is motivated solely by fear during the "extinction" phase. In the studies of "experimental masochism" the motivation underlying the punished behavior is presumably hunger, while in Maier's (1949) studies of fixation there is probably a complex motivational state composed of frustration, hunger, and fear.

Empirical studies of punishment.--Since the results of punishment are directly influenced by the experimental situation, methods, and type of punishment applied, it is of ten difficult to form generalizations from the empirical evidence. Indeed, Stone, in a review of the effects of punishment in serial learning, has concluded that "...the task of resolving conflicting results... is an all but impossible one" (1950, pp. 197-198). Thus, the present review only covers those studies deemed to be most relevant. Reviews of the empirical findings on punishment have been written by Postman (1947), Stone (1950), and Dinsmor (1955). Quite relevant to the present work is a study by Karsh (1962). She used an 8-ft. straight alley with a grid floor. Rats were first trained to run to a goal box in the last section of the alley for food, then given both food and shock for a number of trials. Karsh found that punishment reduced running speed in direct relation to the strength of shock administered. Also, as the number of shock trials increased, the speed curves dropped according to a decay function which rapidly approached an asymptote. Increased training with a food reward did not seem to increase resistance to punishment, as was reported earlier by Kaufman and Miller (1949). In fact, Karsh found a tendency for overtraining to decrease resistance to the effects of the shock. The effect of shock on 
running speed was consistently greater nearer the goal than at the start of the runway.

Differences between the present experimental situation and that of Karsh (1962) should be noted -- especially the location of the punishment. In her study, shock was given after the rat had entered the goal box; more specifically, when the animal touched the food cup. Also, food deprivation was the drive-establishing operation -- not previous shock-escape trials, as in the present study.

Although some work has been done on the interrelationship of purishment and partial reinforcement, this work is not directly comparable to the present study because a free-responding technique was used. For example, Estes (1944) reported that continuous punishment was more effective initially in suppressing a response, although a partial schedule led to suppression effects which were more resistant to extinction. Using pigeons in a free-responding situation, Azrin and his colleagues have further studied the effects of partial schedules of punishment (e.g., Azrin, 1959; Azrin \& Holz, 1961; Azrin, Holz, \& Hake, 1963). Since methodological differences make these studies not directly comparable to the present one, they are merely noted here without any further attempt to review them.

\section{Escape Learning}

Although escape learning seems to be an important component of the behavior of many species of animal in their natural habitat, it has not been a primary technique in laboratory research. Indeed, Spence, in discussing the role of reinforcement in instrumental learning, commented that his treatment of the subject "...has been concerned only with reward 
learning and not with escape conditioning. We have little or no knowledge concerning the effects of varying the reinforcement (escape from a noxious stiumulus) in the latter type of situation; hence there has been little basis for formulating any theory concerning it" (1956, p. 164).

Since 1956, however, several studies of escape learning have been conducted, providing additional knowledge of the primary variables influencing this phenomenon. The present review deals with those studies most relevant to the present experiment; i.e., studies using a discrete trials procedure, electric shock as the aversive stimulus, and rats as $\underline{S}$.

The acquisition of an escape response has been shown to be a negatively accelerated function of the number of acquisition trials (Amsel, 1950; Sheffield \& Temmer, 1950; Campbell \& Kraeling, 1953; Ketchel, 1955; Bower, 1960). Similarly, extinction in an escape situation has been found to be a negatively accelerating function of number of extinction trials (Sheffield \& Temmer, 1950; Campbell \& Kraeling, 1953; Jones, 1953; Bower, 1960). Also, Bower, Fowler, and Trapold (1959) varied the amount of shock reduction upon escaping into a goal box which had varying intensities of shock on its grid floor. Their results indicated that the learning of an escape response was an increasing function of the amount of shock reduction.

The empirical evidence is in accord in showing that rate of acquisition of an escape response is a function of shock intensity (Amsel, 1950; Campbell \& Kraeling, 1953; Ketche1, 1955; Trapold \& Fowler, 1960). The evidence relating shock intensity to asymptotic performance, however, requires further clarification. Amsel, as well as Campbell and Kraeling, found that the performance curves for different intensities converged at a 
common asymptote. Ketchel reported a divergence of the performance curves for different shock intensities, as did Trapold and Fowler. Their failure to find different asymptotic performances for different shock intensities may have been due to the higher intensities used by Amsel (1950) and Campbell and Kraeling (1953). High intensities may have led to the animals running at maximum speed, thus imposing an artifical ceiling on magnitude of response.

Resistance to extinction of an escape response was found to be greater after ten acquisition trials than after forty by Santos (1960). However, a more systematic study (Martin, 1962) has shown that resistance to extinction was an increasing function of the number of training trials up to sixteen trials. A slight decrease in resistance to extinction occurred in a 32-trial group, a finding which seems to conform to the pattern of the results obtained by Santos (1960). Resistance to extinction has also been found to be a negatively decelerated function of the delay between training and extinction (Melvin, Martin, \& Parsons, 1963). They found a sharp decline in resistance to extinction during the first $18 \mathrm{~min}$. of delay, with little decline thereafter up to a delay of $162 \mathrm{~min}$.

Studies comparing avoidance learning with escape learning are relevant to the present study, in that avoidance procedures involve partial occurrence of shock in avoidance training, animals receive aversive stimulation only during trials on which they fail to avoid; in escape training, they receive the aversive stimulus on every trial. Thus, in the avoidance situation, shock, as well as shock termination, occurs intermittently. As would be expected from the principle of partial 
reinforcement, avoidance learning is more resistant to extinction than escape learning (Sheffield \& Temer, 1950; Jones, 1953). Other variables are present in the avoidance situation, however, which might be responsible for this result, e.g., variable shock duration and variable location of shock in the runway.

Jones (1953) found that an intermittent escape schedule, according to which rats were shocked on only 28 per cent of the training trials, resulted in greater resistance to extinction than a conventional escape procedure. Jones' intermittent escape procedure was similar to the partial reinforcement procedure of the present study. However, there were certain limitations of technique in Jones' study, i.e., padding animals to the goal after ten seconds had elapsed on acquisition and extinction trials, the discarding of trials on which rats jumped over horizontal photocell beams, and manually dropping the animals onto the grid. Thus, the relationship between partial reinforcement and escape learning seemed to require further study.

One might define the occurrence of partial reinforcement in escape learning in another manner. Shock could be given on every training trial, with either shock termination or no shock termination in the goal box. Bower (1960) has taken this approach. He reported that acquisition speed was an increasing linear function of percentage of reinforcement. In addition, a 50 per cent reinforced group was more resistant to extinction than a 100 per cent group. Bower's technique, however, confounds delay of reinforcement with per cent of reinforcement, since all animals were removed from the goal box after $20 \mathrm{sec}$, whether it was electrified or not. If the $20 \mathrm{sec}$. delay period is sufficiently long enough so that the 
withdrawal of the rat from the electrified goal box does not reinforce the running response, as Bower assumes, then the procedure seems methodologically sound. However, the effects of delay of shock termination on escape learning have not been studied, and this methodological question remains unresolved.

While the technique used by Jones (1953) and the present study does not involve the above problem, this technique (intermittent escape training) does lead to variation of the drive state during training. During shock trials, the animals perform the running response under the drive state induced by electric shock -- a stimulus regarded to be a primary source of drive (Brown, 1961). On interspersed non-shock training trials, a gradually learned source of drive, fear, serves to motivate the running response. In instrumental reward learning, however, the animals perform the response during non-reinforced trials under the same drive state as on reinforced trials. Thus, the procedure (intermittent occurrence of shock termination) used by Bower (1960) may be more analogous to studies of partial reinforcement done in a reward learning context. Intermittent escape training seems, nevertheless, to merit study in its own right. And, as Spence has noted, the effects of reinforcement in instrumental escape learning may be quite different from those found in instrumental reward learning (1956, p. 164). 


\section{CHAPTER III}

\section{METHOD}

\section{Subjects}

Eighty naive male hooded rats served as subjects (Ss). Twenty-four rats were of the Long-Evans strain, and the remaining $56 \underline{\text { Ss were obtained }}$ from the rat colony of the Department of Psychology, University of Florida. Rats of both strains were evenly distributed over the eight experimental conditions. The Ss were 90 to 135 days old when first introduced into the experimental apparatus.

\section{Apparatus}

The main components of the apparatus were a starting box and a straight runway, both of which had grid floors and glass lids, plus. a goal box which was fitted with a wooden floor and lid. The starting box (18 in. 1. $\times 3.5$ in. w. $\times 11.5$ in. h., inside) was divided into an upper and a lower compartment by a trap-door floor hinged along one edge 7 in. above the grid floor. A door at the end of the starting box allowed the $\underline{S}$ to be inserted into the upper compartment, and a $4.5 \times 3.5$ in. barrier at the alley end of that compartment prevented the Ss from prematurely escaping into the alley. Upon release of the trap-door floor, the animal fell to the grid floor below.

The runway (6 ft. $\times 3.5$ in. w. $\times 11.5$ in. h. inside) was homogeneous throughout except for narrow wooden strips across the top at the 2- and 4-ft. positions. These strips supported cadnium sulphide photocells 
which pointed downward and were energized by infrared light sources below the grid floor. Other vertical light beams and photocells were situated at the juncture of the starting box and alley and at the entrance to the goal box. Through the use of these devices and associated electronic equipment, measurements (to the nearest $1 / 100 \mathrm{sec}$.) were made of starting time (the time that elapsed between the moment that the trap-door floor dropped $\mathbf{S}$ onto the grid until he interrupted the first light beam) and the times consumed in traversing each of three $2-\mathrm{ft}$. alley segments. Alley time was computed simply by adding the times recorded for each of the three 2-ft. segments.

The goal box (18 in. $1 . \times 10$ in. w. $x 11.5$ in. h., inside) had a wooden floor and a hinged top, and served as a "safe" region which the rats could enter to escape shock. In contrast to the starting box and runway, which were painted light gray, the goal box was painted black. This contrast may have served to minimize fear in the latter region: A guillotine door at the entrance to the goal box prevented $\underline{S}$ from retracing.

The grid floors were constructed of $3 / 32$ in. stainless steel rods set into plexiglass side rails at 0.5 in. intervals. The shocking current (60 cycles A.C.) was provided by a variable-voltage auto-transformer connected to the grid through a 10,000 ohm series resistor. The six 1-ft. grid segments in the runway and the 18-in. segment under the starting box were wired so that they could be selectively energized. The open circuit voltage across the grid sections was measured by a voltmeter, and the shock intensities given in the "procedure" section were read from this meter. 
A buzzer mounted on the side of the starting box served as a CS, producing both a clearly audible sound and vibrations of the starting box. During its operation, it was turned on and off at $0.5 \mathrm{sec}$. intervals by a motor-driven interrupter. The sound level in the starting box was measured by a General Radio sound level meter ("C"-scale weighting). It was $61 \mathrm{db}$. (re: .0002 dynes $/ \mathrm{cm}^{2}$ ) without the buzzer turned on, and it increased to $80 \mathrm{db}$. when the buzzer was added, and to $87 \mathrm{db}$. when the relay which released the trap-door floor was activated.

\section{Experimental Design}

The Ss, divided into three major groups, were trained to escape shock by running the length of the alley into a "safe" goal box. One of the three major groups $(\mathrm{N}=20)$ received 100 per cent negative reinforcement, i.e. they received shock on every acquisition trial. A second group $(N=30)$ received shock on 67 per cent of the acquisition trials, while the third group $(N=30)$ was given shock on a 33 per cent schedule during acquisition.

For the partially reinforced groups, shock was assigned randomly • within every six trials, with the following restrictions: (a) shock was assigned randomly within every three trials on the two days having only three training trials, and (b) shock was always present on the first and last trial of an acquisition day, except for the 33 per cent reinforced group which did not receive shock on the last trial of the first acquisition day and the first trial of the last acquisition day.

Following training, the three groups were subdivided in the following manner. The group which received 100 per cent negative reinforcement during training was divided into two groups of ten $\underline{S} s$ each. One of these groups (Group 100-NS) received no shock during "extinction," while the other group 
(Group 100-100) was shocked in the last 4 ft. 으 the alley on every extinction trial. The first term in the group code refers to training, the second to "extinction," with the number referring to the percentage of trials with shock present and "NS" meaning no shock was present on any trial. The group receiving 67 per cent shock trials during training was subdivided into three groups of ten animals each. Group 67-NS received no shock during extinction, while Group 67-100 received shock in the last 4 ft. 으 the alley on every extinction trial. A third group, Group 67-67, received the same percentage of shock trials (in the last 4 ft. of the runway) in extinction as they had (in the entire runway) in training. A similar division was made of the group receiving a 33 per cent shock schedule during training, resulting in Groups 33-NS, 33-33, and 33-100. Each group contained ten Ss. All assignments of $\underline{S}$ s to conditions were made randomly.

Procedure

Preliminary training.--Five days before the $\underline{S}$ s were introduced into the apparatus they were put on a regular feeding schedule calling for approximately $14 \mathrm{gm}$. of Purina laboratory chow per day. Water was available in the living cages at all times. All experimental trials were given when the Ss were approximately $22 \mathrm{hr}$. hungry. During the last two days of the preliminary period the rats were handled for a few min. each day.

The next two-day period was devoted to habituation training, each $\underline{S}$ being permitted to explore all sections of the apparatus for $10 \mathrm{~min}$. per day. On the first day the rat was manually placed onto the grid floor of the starting box, while on the second day it was placed into the upper compartment of the starting box and dropped onto the grid floor. During 
both days the rat spent approximately $80 \mathrm{~min}$. in individual adjoining compartments which measured 8 in. w. $x 8.5$ in. 1. $x 8$ in. h., inside dimersions.

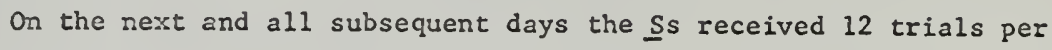
day. The first nine trials on which the Ss received shock were shaping trials in which all animals received identical treatment. Trials 1 and 2 of these nine trials were run with the 6-ft, alley removed and the starting box connected directly to the goal box. The shock was set at $40 \mathrm{v}$. The third and fourth of these nine trials were then given with a temporary 2-ft. alley inserted between the starting and goal boxes, and a shock of $45 \mathrm{v}$. Trials 5 and 6 were then administered with a temporary 4-ft. alley and a shock of $50 \mathrm{v}$. During trials 7,8 and 9 , the entire 6-ft. runway was used, and the shock was set at $55 \mathrm{v}$.

During shaping, training and extinction, an intertrial interval of 9-11 min. was employed. The following procedure was also standard for all three phases. On every trial the $\underline{S}$ was placed into the starting compartment through the end door, after which the guillotine door at the entrance to the goal box was immediately raised. The latter event initiated the following automatically timed sequence of events: (a) after a $4 \mathrm{sec}$. delay the buzzer began to sound, followed $3 \mathrm{sec}$. later by (b) the closing of a relay, which relegased the trap-door floor. The buzzer continued to sound until the infrared beam at the entrance to the goal box was interrupted, an event which also stopped the third-segment clock. The rat was permitted to remain in the dark goal box with the door closed for approximately $20 \mathrm{sec}$. before being removed to an individual waiting cage to await the next trial. The S s were run in squads (replications) 
of eight, each animal representing one condition. The daily food ration was allotted to each $\underline{S}$ approximately $15 \mathrm{~min}$, after it had been returned to its home cage.

Iraining.--Immediately (9-11 min.) after the completion of the nine shaping trials the $\underline{S} s$ were given three training trials. All training trials were given with the shock set at $60 \mathrm{v}$, and using the 6-ft. alley. The Ss received shock on 33, 67, or 100 per cent of the trials, dependind on the group to which they had been assigned. On the next training day all 12 trials were training trials. The following day's trials consisted of three training trials and then nine extinction trials, with no interruption at the end of training.

"Extinction."--During extinction no $\underline{S}$ was ever given shock in the 18 in. starting section or the first $2 \mathrm{ft}$. of the runway. Groups 100-NS, 67-NS and 33-NS never received shock in any part of the alley during extinction. Groups 100-100, 67-100, and 33-100 were given shock in the last $4 \mathrm{ft}$. of the alley on every trial. Groups $67-67$ and $33-33$ received shock in the last $4 \mathrm{ft}$. of the alley on 67 or 33 per cent of the extinction trials respectively. When present in only the last $4 \mathrm{ft}$. of the alley (i.e., in "extinction"), the shock was set at $45 \mathrm{v}$.

As was indicated above, immediately following the last three training trials, the $\underline{S} s$ were given nine extinction trials. Thus, an animal had a 9-11 min. intertrial interval between its last training trial and first extinction trial. This procedure was initiated to reduce the number of Ss which might extinguish on the very first trial of extinction. Extinction trials were continued for seven additional days at the rate of 12 trials per day, provided the $\underline{S} s$ continued to run. If an animal failed to reach 
and enter the goal box within a criterion time of $60 \mathrm{sec}$, extinction trials were discontinued and arbitrary time scores of $60 \mathrm{sec}$. were entered for that $\underline{\underline{S}}$.

The median was taken as the best measure of an animal's performance for any one day, and its reciprocal was the unit used in the analysis of variance of the data. Speed scores in $\mathrm{ft} / \mathrm{sec}$. were obtained by multiplying the reciprocals by appropriate distance constants. 


\section{CHAPTER IV}

\section{RESULTS}

\section{Acquisition}

Since performance during extinction was the main concern of the present study, no extensive analysis of the training data was made. Data for the last training trial were analyzed, however, since (a) this trial represented the relative performance of the groups immediately

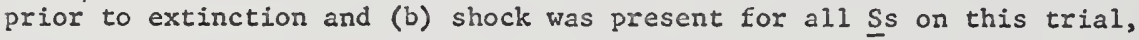
thus all groups had a relatively equivalent amount of shock-produced $\underline{D}$ present during this trial.

In order to convert alley running time into speed, each $\underline{s}$ 's time score on the last training trial was converted into its reciprocal. Means and standard deviations of these data for all eight groups are shown in Table 1 in the Appendix. The means of the eight experimental groups were compared in a simple analysis of variance, which revealed virtually no effect of "groups" (F<I) for these data. A summary of this analysis of variance is found in Table 2 of the Appendix.

Number of Trials to Extinction

Figure 1 shows the mean number of trials to extinction for each of the eight groups. It is obvious in the figure that shock in the last $4 \mathrm{ft}$. of the alley on 100 per cent of "extinction" trials led to greater resistance to extinction than no shock, regardless of the percentage of shock trials during training. This, of course, reflects the "vicious circle" phenomenon. 


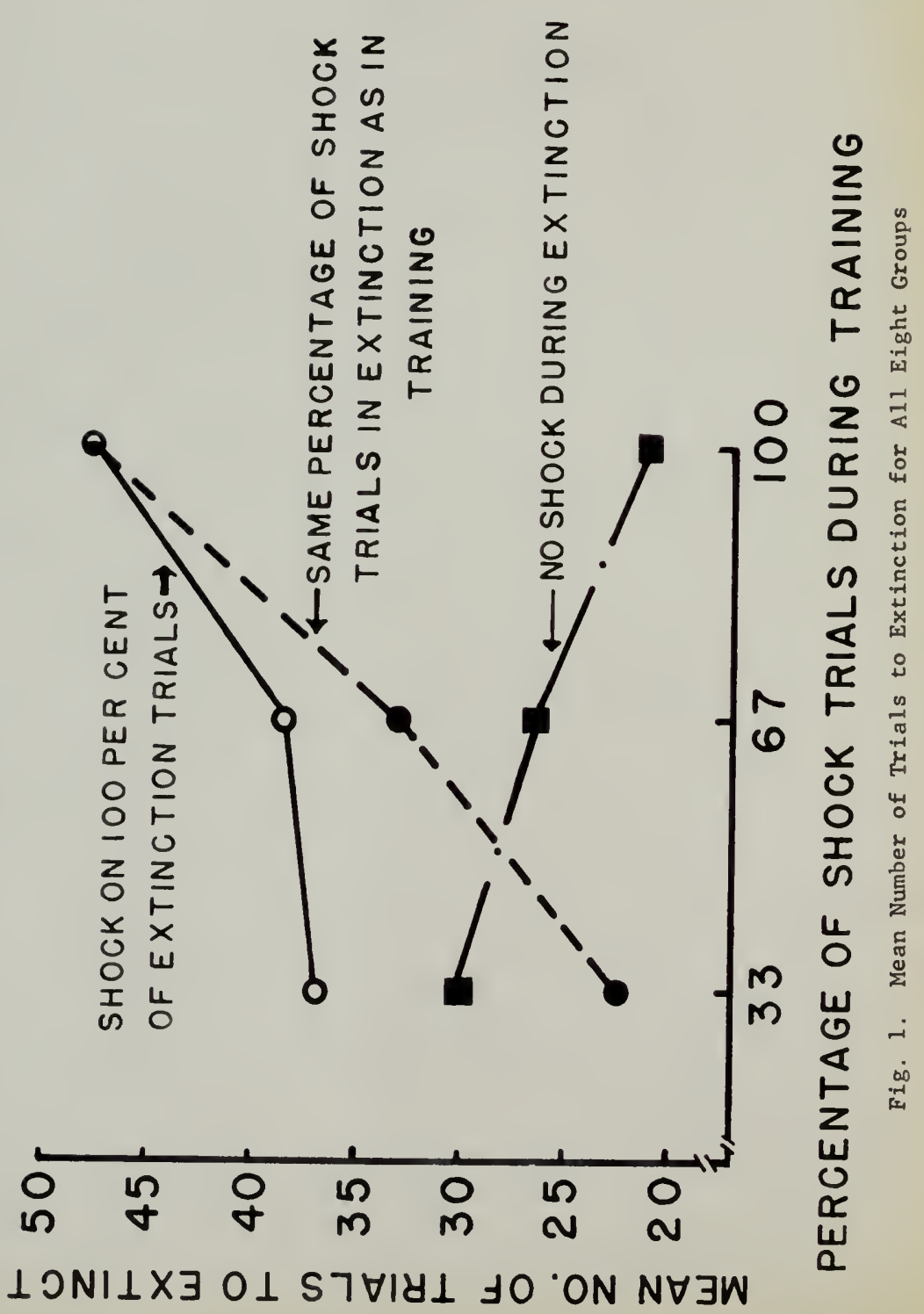


A two by three factorial analysis of variance for groups 100-100, 67-100, 33-100, 100-NS, 67-NS, and 33-NS indicated that this effect was highly significant $(p<.001)$. A summary of this analysis is shown in Table 3 in the Appendix.

Contrary to expectation, partial shock schedules in training did not appear to facilitate performance of the groups receiving 100 per cent shcok in extinction. If anything, a reverse trend occurred, as is shown in Figure 1. The effect of percentage of shock trials during training on performance in extinction for S s receiving no shock in extinction (Groups 100-NS, 67-NS, and 33-NS) was consistent with expectations. However, since the $F$ ratio for the interaction effect failed to reach significance (refer to Table 3), further evaluation (post mortem) seemed unjustified. A main effect of percentage of shock during training was, as the figure shows, absent.

To evaluate the "discrimination hypothesis" as applied to the facilitative effects of shock in the present situation, Groups 67-100 and 33-100 were compared with Groups $67-67$ and $33-33$ in a two by two factorial analysis of variance. A summary of this analysis is shown in Table 4 in the Appendix. The groups shifted to 100 per cent shock trials in extinction were significantly more resistant to extinction than groups (67-67 and 33-33) receiving the same percentage of shock trials in extinction as during training $(\mathrm{p}<.05)$. The above differences are also clearly indicated in Figure 1 . In this analysis, the difference due to percentage of shock trials and the interaction effect were not significant. The results of this analysis fail to support the discrimination hypothesis as an explanation of the facilitative effects of shock in this type of situation. They are, however, in accord 
with the theoretical explanations of both Mowrer (1950) and Guthrie (1935). This conclusion is further supported by an examination of the differences among Groups 100-100, 67-67, and 33-33. According to a "perceptual change" or discrimination hypothesis, these groups should be equally zesistant to extinction, since they experienced "equal" change from acquisition to extinction. An examination of Figure 1 reveals that this was not the case; the higher the percentage of shock trials, the greater was the resistance to extinction. A simple analysis of variance (see Table 5 in the Appendix) revealed a significant "groups" effect $(p<.05)$. This upward trend can be attributed completely to percentage of shock during extinction since, when there is zero shock during extinction, the trend is in a downward direction.

\section{Alley Speed}

To evaluate the effect of introducing shock during the performance of a response (or a homogeneous chain of responses), alley speed was employed as another dependent variable.

Figure 2 shows the speed in which the entire $6 \mathrm{ft}$. alley was traversed by each of the eight groups over four extinction days. Each point represents a mean of ten reciprocals which has been multiplied by six to yield $\mathrm{ft} . / \mathrm{sec}$. Each of the reciprocals was based on an individual s's median running time for the daily trials.

A mixed factorial analysis of variance (Lindquist, 1956) performed on the datal for Groups 100-NS, 67-NS, 33-NS, 100-100, 67-100, and 33-100,

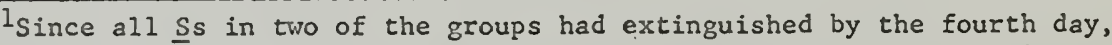
only data from the first three days were used in the statistical analyses of the speed measures.
} 

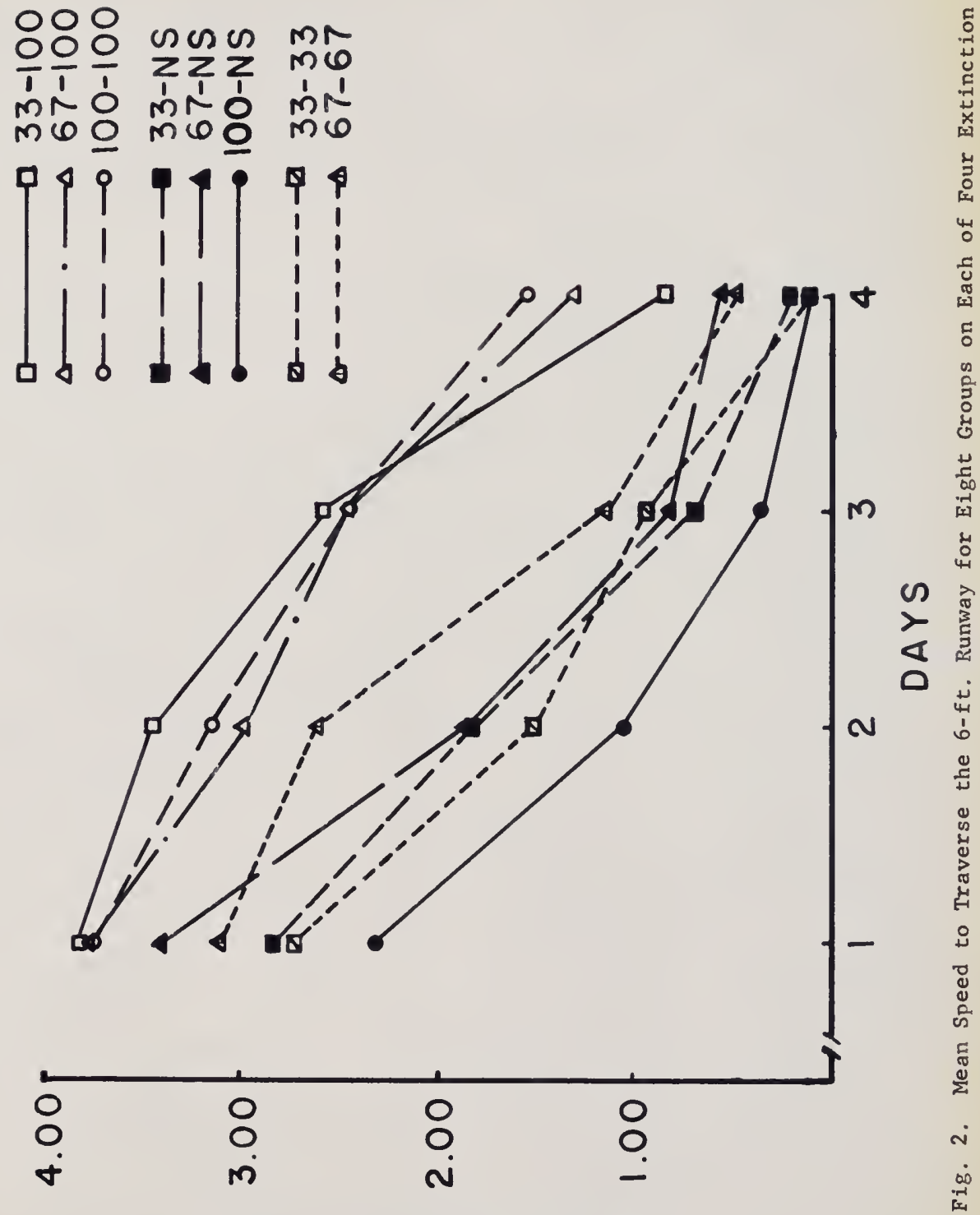

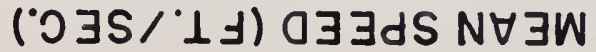


showed a highly significant effect for 100 per cent versus no shock during extinction $(p<.001)$. This analysis is summarized in Table 6 of the Appendix. Again, the administration of shock in the last $4 \mathrm{ft}$. of the alley was found to prolong the extinction process, i.e., the "vicious circle" phenomenon occurred.

Extinction, however, did take place, as the "days" effect was significant $(p<.001)$. The interaction of "days" by extinction treatments was also significant $(p<.001)$, groups receiving shock during extinction having a lower rate of extinction than non-shocked groups, in addition to running faster overall days. The interactions of percentage of shock trials during training with either "days" or extinction conditions were not significant. To evaluate certain theories of the facilitative effects of shock in this type of situation, a comparison was made of Groups 67-100 and 33-100 with Groups 67-67 and 33-33. Figure 2 indicates that the two groups that received 100 per cent shock in extinction were superior to the groups that received identical percentages of shock trials in both training and extinction. Analysis of variance (refer to Table 7 of the Appendix) revealed that this effect was highly significant $(p<.001)$. Thus, the results support the theories of Mowrer (1950) and Guthrie (1935), rather than a discrimination or perceptual change theory. A further test of the latter theory was made through a comparison of Groups 100-100, 67-67, and 33-33. If the discrimination hypothesis is regarded as a complete explanation of the facilitative effects of shock, then no differences between these groups should have been present. Some systematic differences are evident in Figure 2; however, they failed to reach an acceptable level of significance $(F=2.84$, $\mathrm{df}=2 / 27, \mathrm{p}<.10$ ). A summary of this analysis of variance is shown in Table 8 of the Appendix. 
Section 1 Speed

Of primary importance was a comparison of group speeds in the first section of the runway. By means of such a comparison the effects of . shock in extinction could be evaluated without the inclusion of the energizing effect of the shock on the specific response. That is, the behavior in section 1 was followed by punishment (shock), rather than the punishment being introduced during the behavior, as occurs in the total running response and in all other sections.

The running speed data for the first section of the alley are shown in Figure 3. As the curves in this figure indicate, speed of running decreased over days for all groups. Although groups receiving continuous shock (Groups 100-100, 67-100, and 33-100) or no shock during extinction (Groups 100-NS, 67-NS, and 33-NS) showed negligible differences on the first day, on the following days the shocked groups were superior. The analysis of variance for these data (refer to Table 9 in the Appendix) showed that the effect of shock versus no shock in extinction did not reach an acceptable level of significance, $(F=3.37, d f=1 / 54, p<.10)$. However, the interaction of the above effect with "days" was significant $(p<.05)$, indicating that the presence of shock significantly lowered the rate of extinction, even in a section of the runway containing no shock. Percentage of reinforcement during training did not produce any noticeable systematic effects on this response measure, and the statistical analysis (shown in Table 9) revealed no significant differences.

In order to test certain theoretical explanations of the facilitative effects of shock, Groups $67-100$ and 33-100 were compared with Groups 67-67 and 33-33. Although Figure 2 indicates that the 100 per cent shock groups 


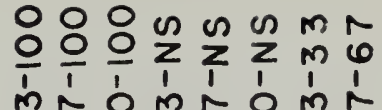

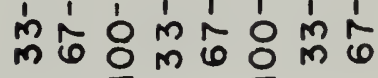

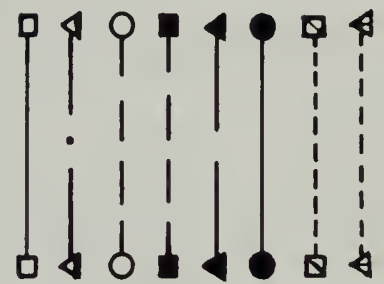
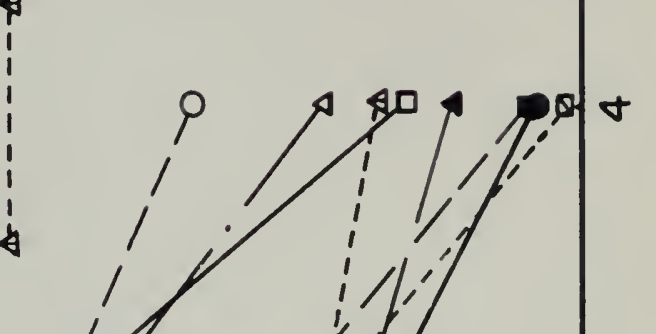

ֻ
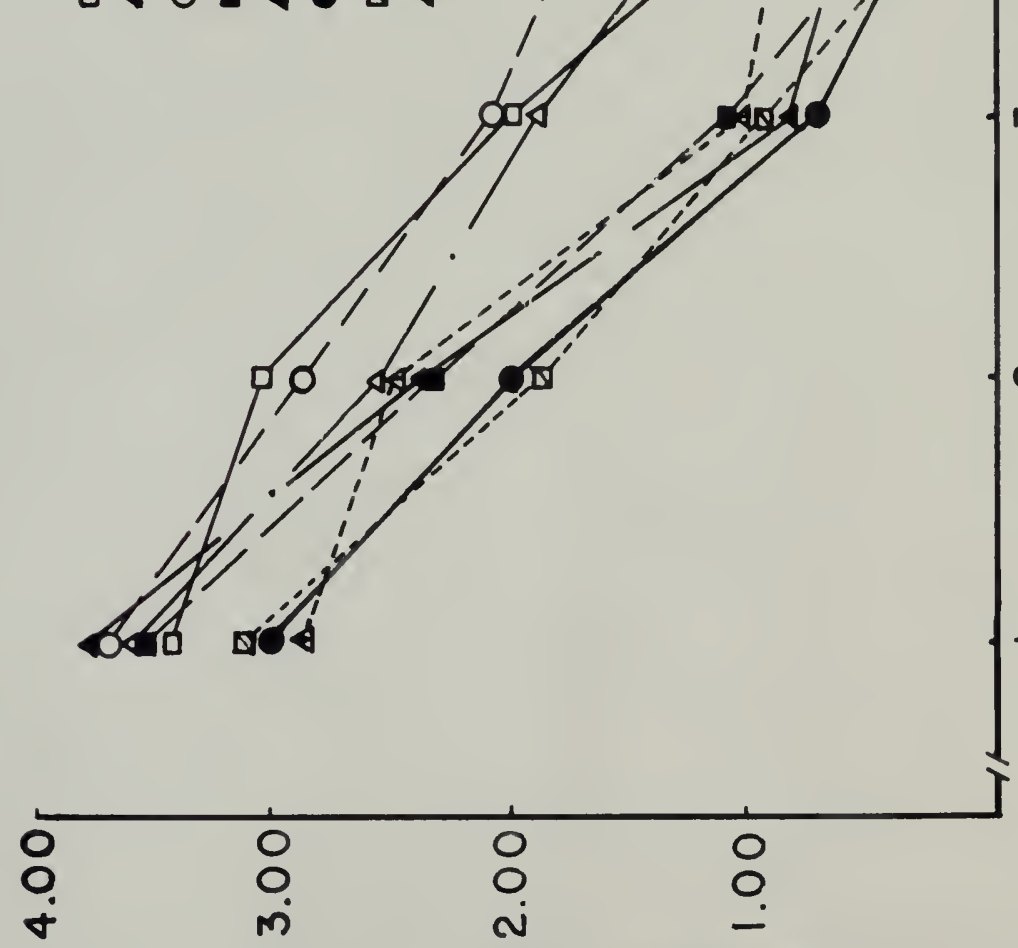

$(0 \exists S / \perp\lrcorner) 0 \exists \exists d S N \forall \exists W$ 
were superior, thus favoring Mowrer's theory over a discrimination theory, the differences were not statistically significant. Table 10 in the Appendix presents a summary of the analysis of variance.

An examination of the relative performance of Groups 100-100, 67-67, and 33-33 is also pertinent to the evaluation of the theoretical explanations. The discrimination hypothesis would predict equal resistance to extinction for these three groups. As did previous response measures, Section 1 speed revealed systematic differences favoring, respectively, Group 100-100, 67-67, and 33-33. However, a statistical analysis of these data provided no basis for rejecting the null hypothesis (refer to Table 11 in the Appendix).

Speed Across Sections

Runnirg speed in the three alley sections averaged over three extinction days is shown in Figure 4. It is apparent that $\underline{S}$ s that received on every trial (in the last two sections of the alley) tended to accelerate, whereas non-shocked rats ran progressively slower as they approached the goal. Analysis of variance applied to these data yielded a highly significant sections by extinction treatments interaction $(p<.001)$. These results are still another manifestation of the vicious circle phenomenon and illustrate how the administration of shock changed the course of the running response. A summary of this analysis can be found in Table 12 of the Appendix.

The only other significant effect in this analysis was the main effect of 100 per cent versus no shock trials in extinction ( $p<.001$ ). This finding is essentially a replication of the extinction treatments main effect as shown previously in the analysis of variance for alley speed (refer to Table 6). 


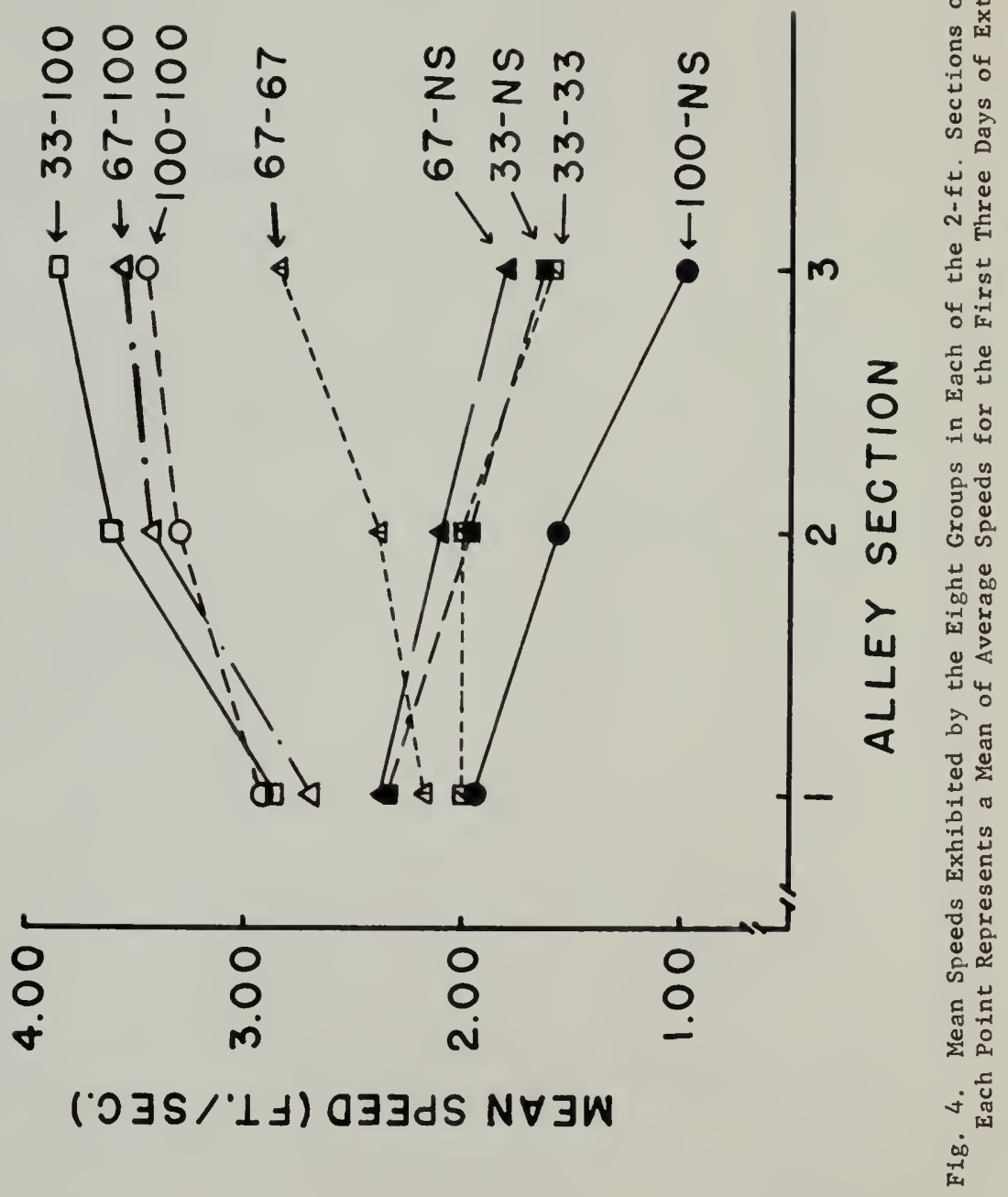


Curves for the groups that received a partial shock schedule during extinction (Groups $67-67$ and 33-33) tended to aiffer from one another. Figure 4 shows that, while Group 67-67 tended to perform similarly to the groups receiving shock on every extinction trial, Group 33-33 performed in the same manner as did the non-shocked groups.

When compared with Groups $67-100$ and 33-100, a statistical analysis indicated that the partial shock groups (67-67 and 33-33) ran significantly slower $(p<.001)$. The effect of "sections" was also significant (p<.001), the Ss tending to run faster as they progressed down the alley. This finding is qualified, however, by the fact that both the interaction of extinction treatments with "sections" and the triple interaction were significant $(p<.001 ; p<.01)$. These findings were interpreted as reflecting the different trend shown by Group 33-33, which showed a decrement in speed in section 3 (whereas the other three groups showed an increment). A summary of the analysis of variance for these data is shown in Table 13. 


\section{CHAPTER V}

\section{DISCUSSION}

\section{Facilitative Effects of Punishment}

The results of this study show that, contrary to its usual role, punishment facilitated the performance of the punished act. By means of certain experimental procedures, animals were trained to consistently approach a normally aversive stimulus. This persistence in self-punishment, or "vicious circle" behavior, was reflected in all the response measures obtained: section 1 speed, alley speed, speed gradients over sections and number of trials to extinction. Section 1 speed is especially important, as it enables us to look at an approach response which leads to punishment, yet is facilitated by this punishment. The alley speed measure provides an example of a response which is punished in its latter stages; yet, it, too, was strengthened by the administration of punishment.

Under the conventional assumption that punishment should deter or weaken reactions, it would be expected that the more frequent the punishment, the more the response should be suppressed. In general, the reverse occurred. Groups receiving shock on every extinction trial not only outperformed non-shocked groups, but outperformed groups which received shock on some percentage (33 or 67) of extinction trials also.

This latter finding is relevant to the finding of Brown et al. (in press) that the more sections of the alley which were electrified, the greater was 
the resistance to extinction. Gwinn (1949) has shown that a moderate punishing shock led to greater performance than a weak shock -- a finding also in opposition to a simple punishment hypothesis.

In general, the results of the present experiment are in accord with the previous findings of Whiteis (1956), Gwinn (1949), Solomon et al. (1953), and Brown et al. (in press) and are contrary to the findings of Moyer (1955, 1957) and Seward and Raskin (1960). Brown et al. have discussed possible reasons for the previous failures to obtain the vicious circle phenomenon. They maintained that the intensity of the punishing stimulus should be moderate, the to-be-punished response should be well established, and that the shift from training to extinction must be gradual. It should be noted that the present study, which in general met these requirements, was able to demonstrate the facilitative effects of punishment quite clearly in this situation.

Although most of the $\underline{S} s$ eventually extinguished, two rats, both in Group 100-100, ran the full 93 trials with little diminution in speed. It might be said that these animals were, indeed, caught in a "vicious circle." Theoretical considerations.--Brown et al, have considered three theoretical explanations of the vicious circle phenomenon. One such explanation is that of Mowrer (1950), who emphasized the role of conditioned fear in the maintenance of this type of perseverative behavior. According to Mowrer, fear is conditioned to the cues present in the start box and alley during the original escape training. During extinction this fear drives the $\underline{s}$ to the goal box, thus reducing the fear and reinforcing the running response. However, in performing the act the animal also gets shocked, thus preventing or retarding the process of fear extinction which might, 
otherwise, lead to the extinction of the running response. Mowrer (1960) also suggested that the fear elicited by shock in the latter part of the alley might generalize back down the alley to the starting section. He held that this effect could result from a failure of discrimination, citing evidence from Whiteis (1956) to support this contention. Whiteis had found that if the shock area was clearly marked off from the nonshock area, $\underline{S}$ did not get into and persist in the "vicious circle." Also, Brown et al (in press) have noted that shock reduction is also a strong reinforcer for running, and that shock onset should energize in-progress running responses. Thus, shock becomes not only a signal for fear reduction but for shock termination. It may be that the shock onset reinforces the rat's fear, but that cues present when the $\underline{S}$ is running through the shock become secondarily reinforcing, since, according to Mowrer (1960), a cue signalling the termination of fear and pain should come to elicit "hope."

Mowrer assumes that fear is established through a process of classical conditioning, a working assumption for many experimenters (Brown, 1961). The importance of this assumption in the present situation is discussed later.

Another theory possessing explanatory value in the present context is that of Guthrie (1934, 1935). According to his concept of negative adaptation, noxious stimuli lose their power to evoke escape responses if repeatedly presented when responses that are incompatible with escape are prepotent. Thus, the noxious stimulus loses its negative properties to the degree that it becomes a conditioned cue for the incompatible responses. Guthrie stated that "It is not the feeling caused by punishment, but the specific action 
caused by punishment that determines what will be learned" (1934, pp. 457458). During escape training, then, the shock became a cue for responses of running forward. In extinction, the shocked animals persisted longer in running because shock in the last $4 \mathrm{ft}$. of the runway evoked and maintained forward-going behavior.

Another interpretation of the vicious circle phenomenon can be made in terms of a "discrimination" or "perceptual change" hypothesis. Such a hypothesis states tinat the greater the similarity between acquisition and extinction conditions, the greater the resistance to extinction. Thus, if shock was used in training, $\underline{S} s$ shocked (in part of the alley) during extinction experienced less of a change from training to extinction than did animals receiving no shock during extinction, and, thus, should extinguish more slowly.

An attempt was made to evaluate the relative applicability of the latter explanation by running two groups with intermittent shock schedules. If the discrimination hypothesis is an adequate explanation of the facilitative effects of shock in this type of situation, it would follow that groups receiving identical percentages of shock during training and extinction (67-67 and 33-33) should be superior to groups shifted to a higher percentage of shock in extinction (67-100 and 33-100). Both Mowrer's and Guthrie's theory, however, would predict the reverse to occur.

It should be noted that (relevant to Mowrer's theory) the extinction situation is really the continuation of an acquisition series for the conditioning of fear for $\underline{S} s$ shocked in the latter part of the alley. If one assumes that fear is classically conditioned, as does Mowrer (1950, 1960), groups on a continuous shock schedule during extinction (67-100 and 33-100) 
would be more fearful during extinction than partially reinforced groups $(67-67$ and $33-33)$. This conclusion is based on a number of studies showing that the acquisition of a classically conditioned response is seriously retarded by partial reinforcement (Pavlov, 1927; Grant \& Schipper, 1952; Razran, 1955; Reynolds, 1958). Thus, the higher the percentage of shock trials during extinction, the more fear would be present to motivate the running response, if, as Mowrer has hypothesized, this fear generalizes throughout the alley.

The bulk of the evidence obtained in the present study indicates that groups shifted to 100 per cent shock during extinction were more resistant to extinction than those continued on their original shock schedule. These findings are consistent with either Mowrer's or Guthrie's theory, and are in opposition to a discrimination or perceptual change hypothesis.

Further evidence against the discrimination hypothesis as an explanation of this behavior was found through an examination of the relative resistance to extinction of Groups 100-100,67-67, and 33-33. If one accepts the discrimination hypothesis as an explanation of the vicious circle phenomenon, it follows that these three groups (which experienced "equal" change from acquisition to extinction) would be equally resistant to extinction. The results indicate that this was not the case; on all measures, the greatest resistance to extinction was found in Group 100-100, Group 67-67 was intermediate, and Group 33-33 was the least resistant. Although the differences between the groups were significant only in the case of number of trials to extinction, the consistency of the findings, in conjunction with the previous comparisons, casts serious doubt upon the ability of a 
simple discrimination hypothesis to account for these data. Moreover, the above mentioned finding (that the higher the percentage of extinction shock, the more resistance there was to extinction) is supportive of both Mowrer's and Guthrie's theory. This upward trend can be attributed completely to percentage of shock during extinction since, when there is no shock during extinction, the trend is in a downward direction. This finding, that the more frequent the punishment, the more the punished act was facilitated, is the reverse of what would be expected according to a simple punishment hypothesis. Gwinn (1949) also compared groups which received either 33 or 100 per cent shock during extinction, finding no significant differences between them. However, he had predicted that the group receiving shock on every extinction trial would be superior, on the basis that the fear-drive motivating the punished act would increase with the frequency of punishment.

Effects of Partial Reinforcement upon Resistance to Extinction of an Escape Response

The results indicate that there was a consistent trend for the groups which received shock on 67 or 33 per cent of the training trials to be more resistant to extinction than a group shocked on every training trial. However, none of the comparisons were statistically significant. The direction of the differences was in accord with the results of a related study by Jones (1953), who interpreted his findings in terms of the discrimination hypothesis. During intermittent escape training, there are certain trials on which no UCS is presented, these trials being identical to extinction trials. Thus, this procedure makes the acquisition conditions more similar to extinction conditions than does a training schedule involving shock on every trial. However, we have already seen that this 
theory received little support in the present data.

Both the results obtained by Jones and those of the present study can be interpreted in terms of Mowrer's (1950) two-factor theory. According to Mowrer, fear, in this type of situation, is classically conditioned to the cues present in the alley during training. The running response, however, is instrumentally conditioned through the mechanism of drive reduction (which is, in this case, shock termination). The lack of significant results found by the present study might be attributed to the differential effects of partial reinforcement on classical as opposed to instrumental conditioning. It has been shown that the acquisition, and in some cases the resistance to extinction, of a classically conditioned response is seriously retarded by low percentages of reinforcement (Pavlov, 1927; Grant \& Schipper, 1952; Razran, 1955; Reynolds, 1958; Lewis, 1960). On the other hand, a number of studies have shown that partial reinforcement leads to greater resistance to extinction (of instrumentally conditioned responses) than continuous reinforcement (Lewis, 1960). Thus, the use of an intermittent escape procedure might have led to less conditioned fear but also to the establishment of a more stable running response. These results would more or less cancel each other, and thus have led to the lack of significant differences found among the three groups which received different percentages of reinforcement.

The above explanation, however, does not account for Jones' (1953) finding that intermittent escape training led to greater resistance to extinction than did a continuous escape procedure. Intermittent escape training may have a slight facilitative effect on resistance to extinction, as was found by the present study. This slight effect may have been 
increased by an artifact in the procedure used by Jones. In Jones' study, after $10 \mathrm{sec}$. (during both acquisition and extinction), if the $\underline{S}$ had not entered the goal box, he was paddled into it. Thus, during acquisition the intermittent escape group received non-shock (i.e., extinction) trials on which, if they had not made the response within the time limit, they were paddled to the goal. This procedure is the classical paradigm for avoidance learning, if paddling is considered aversive (which does not seem unreasonable, since Jones used this technique to drive the $\underline{S}$ into the goal box). The continuous escape group never received paddling during acquisition in the absence of a shock. Thus, the greater resistance to extinction found in Jones' intermittent escape group might have been due to this "extra" avoidance training.

Effects of Partial Reinforcement during Training on the Facilitative Effects of Punishment

Partial reinforcement during training did not lead to an enhancement of the vicious circle effect, as had been expected. In fact, the 100-100 group tended to be the most resistant to extinction, as well as being the fastest group in the first section of the alley. However, Group 33-33 and Group 67-67 were faster, respectively, in both the second and third sections of the alley. None of these differences were statistically significant. It is probable that any effects of the different training reinforcement schedules were over-ridden by the powerful effects of receiving shock on every extinction trial. Since differential training schedules did not even have a strong (i.e., significant) effect upon resistance to extinction of groups receiving no extinction shock, the above explanation seems tenable. In any case, the facilitative effects of punishment on resistance 
to extinction (i.e., the vicious circle phenomenon) can be demonstrated through the use of an intermittent as well as a continuous escape training procedure.

\section{Speed Gradients Across Alley Sections}

Another point of interest concerning the three groups which were not shocked during extinction relates to the speed gradients (refer to Figure 4). These groups (100-NS, 67-NS, and 33-NS) showed a progressive decrement in speed over the three alley sections, whereas all the shocked groups (with the exception of Group 33-33) increased speed in sections 2 and 3. Similar curves were shown by Brown et al. (in press) for their "short-shock" and "no-shock" groups, except that their short-shock group showed less of a speed increment in the second section. This difference was to be expected, since in their study the second section was non-electrified for this group, while in the present study this section was electrified.

The increase in speed found in Groups 100-100, 67-100, 33-100, and 67-67 can be attributed simply to the energizing effects of shock on the running habit. However, these data do reflect the fact that the animals continued to run through the electrified segments of the runway.

The fact that the three escape learning groups showed a progressive decrement in speed over sections during extinction is rather interesting. Many psychologists have assumed that, in the extinction situation, fear is the source of drive, and that fear reduction occurs as the $\underline{S}$ enters the goal box. This reduction of speed as the $\underline{S}$ nears the goal, however, is the opposite of the usual form of the goal gradient. In fact, it is more similar to an avoidance gradient, e.g., Brown (1948), if one considers that the nearer to the start box the $\underline{S}$ is, the faster he is running 
away from it, and that shock onset occurred in the start box. However, the animals were not shocked just in the start box, but throughout the runway.

Two explanations of this "reverse goal gradient" seemed to have potential usefulness. It may be that since UCS onset occurs in the start box, both the start box and that end of the alley were more fear-arousing, since the onset of a noxious UCS has been found to be an important variable controlling the strength of fear (Mowrer \& Solomon, 1954; Kimble, 1961). Thus, as the $\mathrm{S}$ ran down the alley, his fear, and consequently his running speed, diminished.

The second explanation involves the possibility that both proprioceptive and external cues in the latter section of the alley become associated with shock termination, therefore acquiring secondary reinforcement properties (Crowder, 1959 ; Mowrer, 1960). According to Mowrer, "hope" or "type-2 secondary reinforcement" would become conditioned to these cues -a process which might have resulted in a reduction of fear near the goal. Either or both of these explanations might account for this reverse goal gradient.

\section{General Considerations}

A final note on the relationship between the "experimental self-punishment" established in the present study and other pathological behavior seems in order. Inasmuch as this type of perseverative behavior involves consistent approach to normally aversive stimuli, Brown et al. (in press) have labeled it "masochistic-like." Yet, human masochism is commonly thought of as a phenomenon in which pain becomes an end in itself, i.e., the maso.. is rewarded rather than punished by pain. If this conception is 
true, it offers no small problem for homeostatic notions of motivation and behavior. Quite relevant to this problem is a comment by Mowrer, who stated that "As Brown (1955) has pointed out, all goal seeking behavior involves a detour 'through pain' -- be it only the factor of effort, apprehension, or the like; and it is only when the 'punishment' is great and obvious, with the satisfaction subtle or obscure, that confusion arises" (1960, p. 436). In situations where the "detour through pain" facilitates an original non-adaptive response, the organism may be then caught in the vicious circle. The solution to the practical problem of "breaking" such a vicious circle undoubtedly lies in a further understanding of those conditions under which it is established and maintained. 


\section{CHAPTER VI}

\section{SUMMARY}

The present experiment explored the effects of different percentages of punishment during both acquisition and extinction on the resistance to extinction of an escape response. In certain situations, some investigators have shown that punishment does not hasten the extinction of an escape response, but rather leads to a marked increase in resistance to extinction. Mowrer has referred to this type of behavior as the "vicious circle" phenomenon.

Eighty hooded rats were divided into eight groups of ten $\underline{S} s$ each. All Ss were trained to escape from an electrified start box and 6-ft. alley into a safe goal box. During training, shock was present on 33 , 67, or 100 per cent of the trials, depending on the condition to which the rat was assigned. During subsequent "extinction" trials, shock was never present in the start box or the first 2-ft. of the alley. However, certain groups received shock in the last 4-ft. of the runway during 33 , 67, or 100 per cent of these trials. Three other groups never received shock during extinction. These procedures resulted in the formation of the following groups: 100-NS, 67-NS, 33-NS; 100-100, 67-100, 33-100; and 67-67 and 33-33 (the first numbers refer to the percentage of shock during training, the second to the extinction percentage, and NS represents the no shock condition). 
The response measures were: (a) number of trials to extinction (b) alley running speed and (c) running speed in each of the 2-ft, alley sections.

The results indicated that the groups which received shock on every extinction trial (100-100, 67-100, and 33-100) were the most resistant to extinction. There were no significant differences among these three groups. Intermediate in terms of extinction performance was Group 67-67. The remaining groups (100-NS, 67-NS, 33-NS, and 33-33) were the least resistant to extinction. of the three non-shocked (during extinction) groups, the partially reinforced groups were consistently but non-significantly more resistant to extinction than a continuously reinforced group. Groups shifted to a 100 per cent shock schedule in extinction (33-100 and 67-100) were more resistant to extinction than groups continued on the same percentage (33-33 and 67-67).

The major conclusions were:

1. Contrary to what a simple punishment hypothesis would predict, punishment on every extinction trial led to an increase in the resistance to extinction of an escape response. This "vicious circle" phenomenon occurred regardless of the percentage of reinforcement during training.

2. In general, the more frequent the punishment, the more the punished act was sustained.

3. The percentage of reinforcement during training did not have any significant effect on the facilitative effects of punishment.

4. A consistent trend was found for partially reinforced groups to be more resistant to conventional extinction than a continuously reinforced group, in the three groups which received no shock during extinction. 
5. Different speed gradients across the segments of the runway were found, depending on whether or not shock was present during extinction. In general, non-shocked groups ran progressively slower as they neared the goal, whereas shocked groups accelerated as they progressed down the runway.

6. The results are in opposition to a discrimination or perceptual change hypothesis, and are in accord with Mowrer's two-factor theory. Guthrie's concept of "negative adaptation" also seems applicable to the vicious circle phenomenon. 


\section{APPENDIX}


TABLE 1

MEAN AND STANDARD DEVIATION FOR ALLEY RUNNING SPEEDS ( $1 /$ RT) ON THE LAST TRAINING TRIAL FOR ALL EIGHT GROUPS ( $N=10$ PER GROUP)

Group

$\begin{array}{lllllllll}100-\mathrm{NS} & 67-\mathrm{NS} & 33-\mathrm{NS} & 100-100 & 67-100 & 33-100 & 67-67 & 33-33 \\ .677 & .749 & .805 & .651 & .732 & .732 & .739 & .741 \\ .4897 & .5040 & .5634 & .4098 & .5142 & .4492 & .3657 & .4826\end{array}$


TABLE 2

ANALYSIS OF VARIANCE FOR ALLEY RUNNING SPEEDS (1/RT) ON THE LAST TRAINING TRIAL

\begin{tabular}{lcccc}
\hline Source & SS & df & MS & F \\
\hline Groups & .152 & 7 & .022 \\
Error (within cel1s) & 1.841 & 72 & .026
\end{tabular}

TABLE 3

ANALYSIS OF VARIANCE FOR NUMBER OF TRIALS TO EXTINCTION

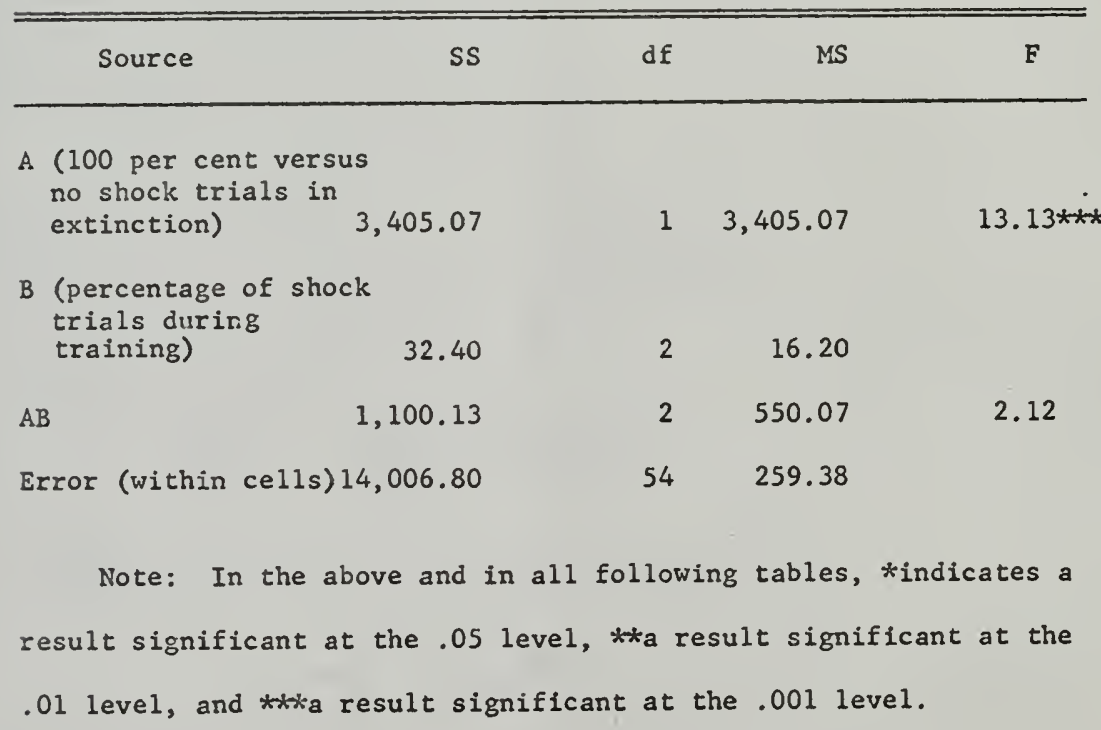


TABLE 4

ANALYSIS OF VARIANCE FOR NUMBER OF TRIALS TO EXTINCTION

\begin{tabular}{|c|c|c|c|c|}
\hline Source & SS & df & MS & $\mathrm{F}$ \\
\hline $\begin{array}{l}\text { A (100 per cent shock } \\
\text { trials in extinction } \\
\text { versus same per- } \\
\text { centage in extinc- } \\
\text { tion as in training) }\end{array}$ & 970.20 & 1 & 970.20 & $4.51 *$ \\
\hline $\begin{array}{l}\text { B (percentage of shock } \\
\text { trials during train- } \\
\text { ing) }\end{array}$ & 378.20 & 1 & 378.10 & 1.79 \\
\hline$A B$ & 198.12 & 37 & 5.35 & \\
\hline Error (within cells) & $3,568.93$ & 39 & 211.25 & \\
\hline
\end{tabular}

TABLE 5

ANALYSIS OF VARIANCE FOR NUMBER OF TRIALS TO EXTINCTION

\begin{tabular}{|c|c|c|c|c|}
\hline Source & SS & $\mathrm{df}$ & MS & $\mathrm{F}$ \\
\hline $\begin{array}{l}\text { Percentage of shock } \\
\text { trials during } \\
\text { training and ex- } \\
\text { tinction }\end{array}$ & $3,228.50$ & 2 & $1,614.25$ & $3.61 *$ \\
\hline Error (within cells) & $12,086.50$ & 27 & 447.65 & \\
\hline
\end{tabular}


TABLE 6

ANALYSIS OF VARIANCE FOR ALLEY RUNNING SPEEDS (1/RT) OVER THREE

DAYS OF EXTINCTION

\begin{tabular}{|c|c|c|c|c|}
\hline Source & ss & df & MS & F \\
\hline Between subjects & 8.971 & $\underline{59}$ & & \\
\hline $\begin{array}{l}\text { A (100 per cent } \\
\text { versus no shock } \\
\text { trials in ex- } \\
\text { tinction) }\end{array}$ & 2.680 & 1 & 2.680 & $24.14 * * * x$ \\
\hline $\begin{array}{l}\text { B (percentage of } \\
\text { shock trials dur- } \\
\text { ing training) }\end{array}$ & .145 & 2 & .072 & \\
\hline$A B$ & .150 & 2 & .075 & \\
\hline Error (b) & 5.996 & 54 & .111 & \\
\hline Within subjects & $\underline{4.598}$ & 120 & & \\
\hline C (days) & 2.606 & 2 & 1.303 & $81.44 * * * *$ \\
\hline $\mathrm{AC}$ & .194 & 2 & .097 & $6.06 * x *$ \\
\hline $\mathrm{BC}$ & .041 & 4 & .010 & \\
\hline $\mathrm{ABC}$ & .015 & 4 & .004 & \\
\hline Error (w) & 1.742 & 108 & .016 & \\
\hline
\end{tabular}


TABLE 7

ANALYSIS OF VARIANCE FOR ALLEY RUNNING SPEEDS ( $1 /$ RT) OVER THREE DAYS OF EXTINCTION

\begin{tabular}{|c|c|c|c|c|}
\hline Source & SS & $\mathrm{df}$ & MS & F \\
\hline Between subjects & 6.583 & 39 & & \\
\hline \multicolumn{5}{|c|}{$\begin{array}{l}\text { A (100 per cent shock } \\
\text { trials in extinction } \\
\text { versus same percent- } \\
\text { age in extinction as }\end{array}$} \\
\hline $\begin{array}{l}\text { B (percentage of } \\
\text { shock trials } \\
\text { during extinction) }\end{array}$ & .023 & 1 & .023 & \\
\hline$A B$ & .132 & 1 & .132 & \\
\hline Error (b) & 5.319 & 36 & .148 & \\
\hline Within subjects & $\underline{2.768}$ & 80 & & \\
\hline C (days) & 1.405 & 2 & .702 & $41.29 * * x$ \\
\hline $\mathrm{AC}$ & .047 & 2 & .024 & 1.41 \\
\hline $\mathrm{BC}$ & .010 & 2 & .005 & \\
\hline$A B C$ & .066 & 2 & .033 & 1.94 \\
\hline Error (w) & 1.240 & 72 & .017 & \\
\hline
\end{tabular}


TABLE 8

ANALYSIS OF VARIANCE FOR ALLEY RUNNING SPEEDS (1/RT) OVER THREE DAYS OF EXTINCTION

\begin{tabular}{|c|c|c|c|c|}
\hline Source & SS & df & MS & $\mathbf{F}$ \\
\hline Between subjects & 4.597 & $\underline{29}$ & & \\
\hline $\begin{array}{l}\text { A (percentage of shoc } \\
\text { trials in training } \\
\text { and extinction) }\end{array}$ & .802 & 2 & .401 & 2.84 \\
\hline Error (b) & 3.795 & 27 & .141 & \\
\hline Within subjects & $\underline{2.330}$ & 60 & & \\
\hline B (days) & 1.187 & 2 & .594 & $55.21 * x *$ \\
\hline$A B$ & .094 & 4 & .024 & 1.26 \\
\hline Error (w) & 1.049 & 54 & .019 & \\
\hline
\end{tabular}


TABLE 9

ANALYSIS OF VARIANCE FOR SECTION 1 RUNNING SPEEDS (1/RT) OVER THREE DAYS OF EXTINCTION

\begin{tabular}{|c|c|c|c|c|}
\hline Source & SS & df & MS & F \\
\hline Between subjects & 73.687 & $\underline{59}$ & & \\
\hline \multicolumn{2}{|c|}{$\begin{array}{l}\text { A (100 per cent versus } \\
\text { no shock trials in } \\
\text { extinction) } \\
4.269\end{array}$} & 1 & 4.269 & 3.37 \\
\hline \multicolumn{2}{|c|}{$\begin{array}{l}\text { B (percentage of } \\
\text { shock trials during }\end{array}$} & 2 & .098 & \\
\hline $\mathrm{AB}$ & .763 & 2 & .382 & \\
\hline Error (b) & 68.458 & 54 & 1.268 & \\
\hline Within subjects & 60.126 & 120 & & \\
\hline C (days) & 32.203 & 2 & 16.102 & $68.23 * x *$ \\
\hline $\mathrm{AC}$ & 2.101 & 2 & 1.050 & $4.45 *$ \\
\hline $\mathrm{BC}$ & .273 & 4 & .068 & \\
\hline$A B C$ & .073 & 4 & .018 & \\
\hline Error (w) & 25.476 & 108 & .236 & \\
\hline
\end{tabular}


TABLE 10

ANALYSIS OF VARIANCE FOR SECTION I RUNNING SPEEDS (1/RT) OVER THREE DAYS OF EXTINCTION

\begin{tabular}{|c|c|c|c|c|}
\hline Source & ss & df & MS & F \\
\hline Between subjects & 61.802 & $\underline{39}$ & & \\
\hline \multicolumn{5}{|c|}{$\begin{array}{l}\text { A (100 per cent shock } \\
\text { trials in extinction } \\
\text { versus same percent- } \\
\text { age in extinction as }\end{array}$} \\
\hline in training) & 3.654 & 1 & 3.654 & 2.28 \\
\hline \multicolumn{5}{|c|}{$\begin{array}{l}\text { B (percentage of shock } \\
\text { trials during train- }\end{array}$} \\
\hline$A B$ & .191 & 1 & .191 & \\
\hline Error (b) & 57.956 & 36 & 1.610 & \\
\hline Withi subjects & 29.225 & 80 & & \\
\hline C (days) & 15.854 & 2 & 7.927 & $46.09 * x * k$ \\
\hline $\mathrm{AC}$ & .298 & 2 & .149 & \\
\hline $\mathrm{BC}$ & .026 & 2 & .013 & \\
\hline$A B C$ & .647 & 2 & .324 & 1.88 \\
\hline Error (w) & 12.400 & 72 & .172 & \\
\hline
\end{tabular}


TABLE 11

ANALYSIS OF VARIANCE FOR SECTION 1 RUNNING SPEEDS ( $1 /$ RT) OVER THREE DAYS OF EXTINCTION

\begin{tabular}{|c|c|c|c|c|}
\hline Source & SS & $\mathrm{df}$ & MS & F \\
\hline Between subjects & 42.297 & 29 & & \\
\hline $\begin{array}{l}\text { A (percentage of shock } \\
\text { trials in training } \\
\text { and extinction) }\end{array}$ & 3.618 & 2 & 1.809 & 1.26 \\
\hline Error (b) & 38.679 & 27 & 1.433 & \\
\hline Within subjects & 25.533 & $\underline{60}$ & & \\
\hline$B$ (days) & 13.363 & 2 & 6.682 & $31.22 * x+x$ \\
\hline $\mathrm{AB}$ & .607 & 4 & .152 & \\
\hline Error (w) & 11.563 & 54 & .214 & \\
\hline
\end{tabular}


TABLE 12

ANALYSIS OF VARIANCE FOR RUNNING SPEEDS (1/RT) AVERAGED OVER THREE DAYS FOR EACH OF THREE ALLEY SECTIONS

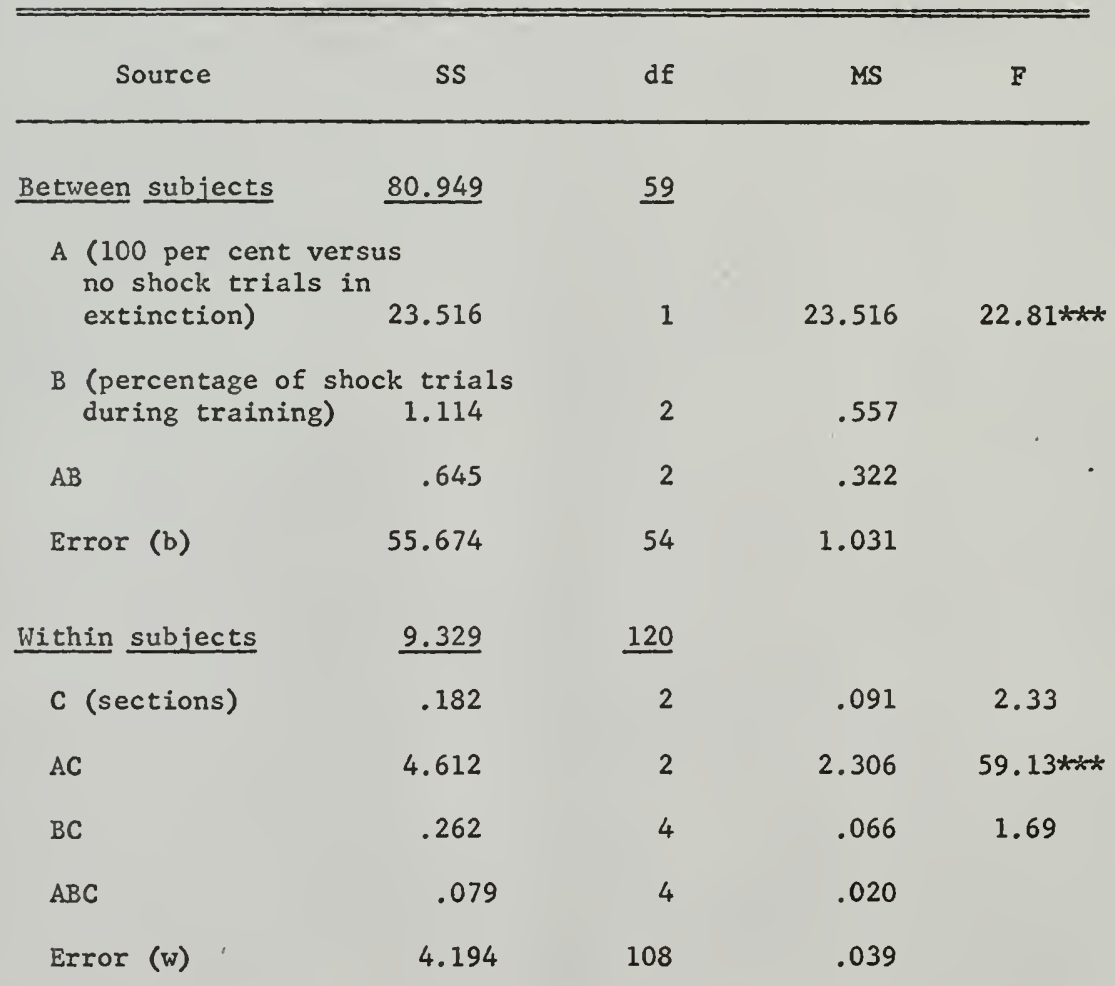


TABLE 13

ANALYSIS OF VARIANCE FOR RUNNING SPEEDS (1/RT) AVERAGED OVER THERE DAYS FOR EACH OF THREE ALLEY SECTIONS

\begin{tabular}{|c|c|c|c|c|}
\hline Source & SS & $d f$ & MS & $F$ \\
\hline Between subjects & 57.284 & 39 & & \\
\hline \multicolumn{5}{|c|}{$\begin{array}{l}\text { A (100 per cent shock } \\
\text { trials in extinction } \\
\text { versus same percent- } \\
\text { age as in training) } 10.361\end{array}$} \\
\hline \multicolumn{5}{|c|}{$\begin{array}{l}\text { B (percentage of shock } \\
\text { trials during train- } \\
\text { ing) }\end{array}$} \\
\hline $\mathrm{AB}$ & 1.228 & 1 & 1.228 & \\
\hline Error (b) & 45.469 & 36 & 1.263 & \\
\hline
\end{tabular}

\begin{tabular}{|c|c|c|c|c|}
\hline Within subjects & 7.238 & $\underline{80}$ & & \\
\hline C (sections) & 1.635 & 2 & 8.18 & $15.25 * * *$ \\
\hline $\mathrm{AC}$ & .910 & 2 & .455 & $8.59 * x-x$ \\
\hline $\mathrm{BC}$ & .255 & 2 & .128 & 2.41 \\
\hline $\mathrm{ABC}$ & .593 & 2 & .296 & $5.59 * *$ \\
\hline Error (w) & 3.845 & 72 & .053 & \\
\hline
\end{tabular}




\section{BIBLIOGRAPHY}

Amsel, A. The combination of a primary appetitional need with primary and secondary emotionally derived needs. J. exp. Psychol., 1950 40, 1-14.

Azrin, N. H. Punishment and recovery during fixed-ratio performance. J. exp. Anal. Behav., 1959, 2, 301-305.

Azrin, N. H., \& Holz, W. C. Punishment during fixed-interval reinforcement. J. exp. Anal. Behav., 1961, 4, 343-347.

Azrin, N. H., Holz, W. C., \& Hake, D. F. Fixed ratio punishment. J. exp. Anal. Behav., 1963, 6, 141-148.

Bower, G. H. Partial and correlated reward in escape learning. I. exp. Psychol., 1960, 59, 126-130.

Bower, G. H., Fowler, H., \& Trapold, M. A. Escape learning as a function of amount of shock reduction. I. exp. Psychol., 1959, 58, 482-484.

Brown, J. S. Gradients of approach and avoidance responses and their relation to level of motivation. J. comp. physiol. Psychol., 1948, 41, 450-465.

Brown, J. S. Pleasure-seeking behavior and the drive-reduction hypothesis. Psychol. Rev., 1955, 62, 169-179.

Brown, J. S. The motivation of behavior. New York: McGraw-Hill, 1961.

Brown, J. S., Martin, R. C., \& Morrow, M. W. Masochistic-like behavior in the rat: Facilitative effects of punishment on resistance to extinction. I. comp. physiol. Psychol., in press.

Brown, J. S., \& Melvin, K. B. Neutralization of an aversive stimulus as a function of number of pairings with a reinforcing event. Unpublished manuscript, University of Florida, 1963.

Campbel1, B. A., \& Kraeling, Doris. Response strength as a function of drive level and amount of drive reduction. I. exp. Psychol., 1953, 45, 97-101.

Crowder, W. F. (University of Illinois) Secondary reinforcement and shock termination. Dissertation Abstr., 1959, 19, 2663. (Abstract)

Dinsmor, J. A. Punishment: I. The avoidance hypothesis. Psychol. Rev., $1954,61,34-46$. 
Dinsmor, J. A. Punishment: II. An interpretation of empirical findings. Psychol. Rev., 1955, 62, 96-105.

Drew, G. C. The function of punishment in learning. I. genet. Psychol., $1938, \underline{52}, 257-267$.

Estes, W. K. An experimental study of punishment. Psychol. Monogr., 1944,57 , No. 3 (Whole No. 263).

Farber, I. E. Response fixation under anxiety and non-anxiety conditions. J. exp. Psychol., 1948, 38, 111-131.

Grant, D. A., \& Schipper, L. M. The acquisition and extinction of conditioned eyelid responses as a function of the percentage of fixedratio random reinforcement. J. exp. Psychol., 1952, 43, 313-320.

Guthrie, E. R. Reward and punishment. Psychol. Rev., 1934, 41, 450-460.

Guthrie, E. R. The psychology of learning. New York: Harper, 1935.

Gwinn, G. T. The effects of punishment on acts motivated by fear. J. exp. Psychol., 1949, 39, 260-269.

Hilgard, E. R., \& Marquis, D. G. Conditioning and learning. New York: Appleton-Century-Crofts, 1940.

Holz, W. C. \& Azrin, N. H. Discriminative properties of punishment. $\underline{J}$. exp. Ana1. Behav., 1961, 4, 225-232.

Hu11, C. L. Principles of behavior. New York: Appleton-Century-Grofts, 1943.

Jones, M. B. An experimental study of extinction. Psychol. Monogr., 1953, 67, (19, Whole No. 369).

Karsh, Eileen B. Effects of number of rewarded trials and intensity of punishment on running speed. J. comp. physiol. Psychol., 1962, 55, 44-51.

Kaufman, Edna L., \& Miller, N. E. Effect of number of reinforcements on strength of approach in an approach-avoidance conflict. J. comp. physiol. Psychol., 1949, 42, 65-74.

Ketchel, Rhoda. Performance in instrumental learning as a function of shock intensity. Unpublished master's thesis, State University of Iowa, 1955. Cited by K. W. Spence, Behavior theory and Conditioning. New Haven: Yale University Press, 1956. pp. 172-173.

Kimble, G. A. Hilgard and Marquis' conditioning and learning. New York: Appleton-Century-Crofts, 1961.

Lewis, D. J. Partial reinforcement: a selective review of the literature since 1950. Psychol. Bu11., 1960, 57, 1-28. 
Lindquist, E. F. Design and analysis of experiments in psychology and education. Boston: Houghton Mifflin, 1956.

Maier, N. R. F. Prustration: the study of behavior without a goal. New York: McGraw-Hill, 1949.

Martin, R. C. Resistance to extinction of an escape response as a function of number of reinforcements. Unpublished master's thesis, University of Florida, 1962.

Masserman, J. H. Principles of dynamic psychiatry. Philadelphia: Saunders, 1946.

Melvin, K. B., Martin, R. C., \& Parsons, G. Resistance to extinction of an escape response as a function of the delay between training and extinction. Unpublished manuscript, University of Florida, 1963.

Miller, N. E. Studies of fear as an acquirable drive: I. Fear as motivation and fear reduction as reinforcement in the learning of new responses. I. exp. Psychol., 1948, 38, 89-101.

Mowrer, 0. H. Learning theory and behavior. New York: Wiley, 1960.

Mowrer, 0. H. Learning theory and personality dynamics. New York: Ronald Press, 1950 .

Mowrer, O. H., \& Solomon, L. N. Contiguity vs, drive-reduction in conditioned fear: the proximity and abruptness of drive-reduction. Amer. I. Psychol., 1954, 67, 15-25.

Moyer, K. E. A study of some of the variables of which fixation is a function. J. genet. Psychol., 1955, 86, 3-31.

Moyer, K. E. The effects of shock on anxiety-motivated behavior in the rat. J. genet. Psychol., 1957, 91, 197-203.

Muenzinger, K. F. Concerning the effect of shock for right responses in visual discrimination learning. J. exp. Psychol., 1948, 38, 201-203.

Muenzinger, K. F. Motivation in learning. I. Electric shock for correct response in the visual discrimination habit. I. comp. Psychol., $1934,17,267-277$.

Pavlov, I. P. Conditioned reflexes. (Trans, by G. V. Anrep). London: Oxford University Press, 1927.

Postman, L. The history and present status of the law of effect. Psychol. Bu11., 1947, 44, 489-563.

Razran, G. H. S. Operant vs. classical conditioning. Amer. J. Psychol., $1955,68,489-490$. 
Reynolds, W. F. Acquisition and extinction of the conditioned eyelid response following partial and continuous reinforcement. J. exp. Psychol., 1958, 55, 335-341.

Sandler, J. Reinforcement combinations and masochistic behavior: a preliminary report. Psychol. Rep., 1962, 11, 110.

Santos, J. R. The influence of amount and kind of training on the acquisition and extinction of escape and avoidance responses. $\mathrm{J}$. comp. physiol. Psycho1., 1960, 53, 284-289.

Seward, J. P., \& Raskin, D. C. The role of fear in aversive behavior. J. comp. physio1. Psycho1., 1960, 53, 328-335.

Sheffield, F. D., \& Temmer, Helena W. Relative resistance to escape training and avoidance training. J. exp. Psychol., 1950, 40, 287-298.

Slutskaya, M. M. Converting defensive into food reflexes in oligophrenics and in normal children. Zh Neuropatol., 1928, 21, 195-210. Reviewed in Razran, G. H. S. Conditioned reflexes in children. Arch. Psychol., 1933,23 , No. 148 .

Solomon, R. L., Kamin, L. J., \& Wynne, L. C. Traumatic avoidance learning: the outcomes of several extinction procedures with dogs. $\mathrm{J}$. abnorm. soc. Psychol., 1953, 48, 291-302.

Spence, K. W. Behavior theory and conditioning. New Haven: Yale University Press, 1956.

Spragg, S. D. S. Morphine addiction in chimpanzees. Comp. Psychol. Monogr. , 1940, 15, No. 7 .

Stone, G. R. The effect of negative incentives in serial learning: II. Incentive intensity and response variability. J. genet. Psychol., 1950,42 , 179-224.

Thorndike, E. L. Educational psychology 3 vols., New York: Teachers College, Columbia University, 1913, Vol. 2.

Thorndike, E. L. The psychology of wants, interests, and attitudes. New York: Appleton-Century, 1935.

Trapold, M. A., \& Fowler, H. Instrumental escape performance as a function of the intensity of noxious stimulus. J. exp. Psychol., 1960, 60, 323326.

Whiteis, U. E. Punishment's influence on fear and avoidance. Harv. Educ. Rev., 1956, 26, 360-373. 
Wilcoxon, H. C. "Abnormal fixation" and learning. J. exp. Psychol., $1952,44,324-333$.

Wolpe, J. Psychotherapy by reciprocal inhibition. Stanford: Stanford University Press, 1958. 


\section{BIOGRAPHICAL SKETCH}

Kenneth Boyd Melvin, Jr., was born at Jamaica, New York, on August 6, 1934. He graduated from Mineola High School in 1952. After attending Hofstra College, I. I., N. Y., for two years, he entered the U. S. Army, and was honorably discharged in 1956. In September, 1957, he returned to Hofstra College and graduated with a B. A. in psychology in February, 1960. During his senior year at Hofstra and the summer of 1960 he was employed as a research assistant by Human Resources Foundation, Albertson, N. Y. In February, 1960, Mr. Melvin enrolled in the Graduate School of the University of Florida. He held a graduate assistantship in the Department of Psychology until June, 1961. At this time he received a University of Florida Graduate Fellowship to work toward the degrees of Master of Arts and Doctor of Philosophy. In February, 1962, he was awarded the degree of Master of Arts.

Kenneth Boyd Melvin, Jr., is married to the former Bernice June Oswald. He is a member and former Treasurer of the local chapter of Psi Chi 

This dissertation was prepared under the direction of the chairman of the candidate's supervisory committee and has been approved by all members of that committee. It was submitted to the Dean of the College of Arts and Sciences and to the Graduate Council, and was approved as partial fulfillment of the requirements for the degree of Doctor of Philosophy.

August 10, 1963

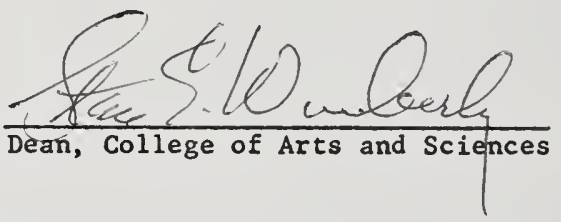

Dean, Graduate School

Supervisory Committee:
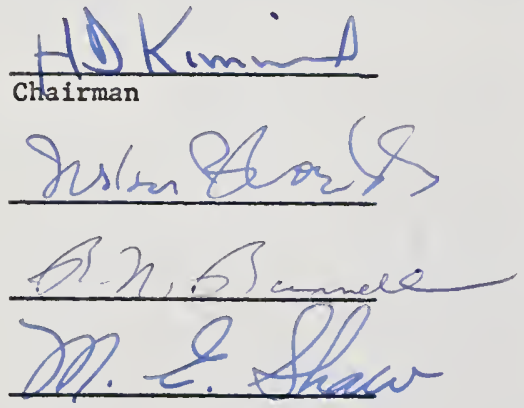

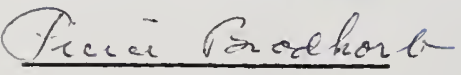


